\title{
In Vitro Demonstration of the Heavy-Atom Effect for Photodynamic Therapy
}

Aoife Gorman, ${ }^{\dagger}$ John Killoran, ${ }^{\dagger}$ Caroline O'Shea ${ }^{\star}$ Tony Kenna, ${ }^{\star}$ William M.

$$
\text { Gallagher }{ }^{*} \text { and Donal F. O'Shea*,† }
$$

Centre for Synthesis and Chemical Biology, Conway Institute of Biomolecular and Biomedical Research, Department of Chemistry and Department of Pharmacology, University College Dublin, Belfield, Dublin 4, Ireland.

\section{SUPPORTING INFORMATION}

\section{General Experimental}

Materials. All commercially available solvents and reagents were used as supplied by Aldrich Chemical Company unless otherwise stated. Compounds 14a-c were purchased from Aldrich Chemical Company. CrEL was purchased from Sigma. SYTOX green was purchased from Molecular Probes (Eugene, OR, USA). $\mathrm{CH}_{2} \mathrm{Cl}_{2}$ was distilled from calcium hydride and stored over molecular sieves. Column chromatography was performed on Merck silica gel 60 Mesh 230-400. Purifications using silica beds were performed on TLC grade Merck silica gel $60 \mathrm{PF}_{254}$. Mg-tetra-tert-butyl phthalocyanine was prepared according to a literature procedure. ${ }^{1}$

Analysis. UV-Visible spectra were recorded on a Cary 50 spectrophotometer. Fluorescence spectra were recorded on a Cary Eclipse spectrophotometer. Mass spectral analyses were performed on a Finnigan MAT Incos $50 \mathrm{~B}$ mass spectrometer (EI) and a Micromass Quattro Micro. High-resolution mass spectra were recorded on a VG analytical 70-E mass spectrometer and Micromass LCT. ${ }^{1} \mathrm{H}$ and ${ }^{13} \mathrm{C}$ NMR spectra were recorded on a Varian $300 \mathrm{MHz}$ FT spectrometer. Chemical shifts are given in ppm 
relative to the standard reference TMS. Melting points were determined on a Reichert Thermovar melting point platform and are uncorrected. Infrared spectra were recorded on a Mattson Instruments Galaxy series FT-IR 3000 spectrometer. Cellular fluorescence microscope images were recorded with an Axio Zeiss fluorescent microscope using a rhodamine filter. Cellular confocal images were recorded with a Leica TCS SL Confocal Laser Scanning microscope using a rhodamine filter.

3-(4-Bromo-phenyl)-1-phenyl-propenone (14d). 4-Bromobenzaldehyde (9.25 g, 0.05 mol), acetophenone $(6.0 \mathrm{~g}, 0.05 \mathrm{~mol})$ and potassium hydroxide $(0.084 \mathrm{~g}, 1.5 \mathrm{mmol})$ were dissolved in ethanol $/ \mathrm{H}_{2} \mathrm{O}(85: 15 \mathrm{v} / \mathrm{v}, 100 \mathrm{~mL})$ and stirred at $\mathrm{rt}$ for $24 \mathrm{~h}$. During the course of the reaction, the product precipitated from the reaction mixture. Filtration of the reaction mixture and recrystallization from ethanol yielded the product as yellow solid (12.1 g, 84\%), m.p. $127-128{ }^{\circ} \mathrm{C} .{ }^{1} \mathrm{H}$ NMR $\left(\mathrm{CDCl}_{3}\right) \delta: 8.01$ (d, 2H), $7.74(\mathrm{~d}, 1 \mathrm{H}), 7.48-$ $7.61(\mathrm{~m}, 8 \mathrm{H}) .{ }^{13} \mathrm{C} \mathrm{NMR}\left(\mathrm{CDCl}_{3}\right) \delta: 190.4,143.6,138.2,134.0,133.2,132.4,130.0$, 128.9, 128.7, 125.0, 122.8. IR ( $\mathrm{KBr}$ disc) $\mathrm{cm}^{-1}: 1658$.

4-Nitro-1,3-diphenyl-butan-1-one (15a). 1,3-Diphenyl-propenone 14a (7 g, 33.6 $\mathrm{mmol})$, nitromethane $(10.25 \mathrm{~g}, 168 \mathrm{mmol})$ and diethylamine $(12.3 \mathrm{~g}, 168 \mathrm{mmol})$ were dissolved in dry methanol $(100 \mathrm{~mL})$ and heated under reflux for $24 \mathrm{~h}$. The solution was cooled, acidified with $1 \mathrm{M} \mathrm{HCl}$ and the resulting precipitate was isolated by filtration. Recrystallization from methanol gave the product as a white solid (7.7 g, 85\%), mp 99$100{ }^{\circ} \mathrm{C} .{ }^{1} \mathrm{H}$ NMR $\left(\mathrm{CDCl}_{3}\right)$ 8: 7.90-7.93 (m, 2H), 7.55-7.60 (m, 1H), 7.41-7.48 (m, 2H), 7.24-7.36 (m, 5H), 4.65-4.86 (m, 2H), 4.18-4.27 (m, 1H), 3.38-3.53 (m, 2H). ${ }^{13} \mathrm{C}$ NMR $\left(\mathrm{CDCl}_{3}\right) \delta: 196.9,139.2,136.4,133.6,129.1,128.8,128.0,127.9,127.5,79.6,41.5,39.3$. 
IR (KBr disc) $\mathrm{cm}^{-1}:$ 1690. EI-MS: $\mathrm{m} / \mathrm{z}$ 269. Anal. Calcd for $\mathrm{C}_{16} \mathrm{H}_{15} \mathrm{NO}_{3}: \mathrm{C}, 71.36 ; \mathrm{H}$, 5.61; N, 5.20. Found C, 71.30; H, 5.66; N, 5.11.

1-(4-Methoxy-phenyl)-4-nitro-3-phenyl-butan-1-one (15b). 1-(4-Methoxy-phenyl)3-phenyl-propenone 14b (10.0 g, $42.0 \mathrm{mmol})$, nitromethane (12.78 g, $0.21 \mathrm{~mol})$ and diethylamine $(15.35 \mathrm{~g}, 0.21 \mathrm{~mol})$ were dissolved in dry methanol $(250 \mathrm{~mL})$ and heated under reflux for $24 \mathrm{~h}$. The solution was cooled, acidified with $1 \mathrm{M} \mathrm{HCl}$ and extracted with $\mathrm{CH}_{2} \mathrm{Cl}_{2}(2 \times 100 \mathrm{~mL})$, dried over sodium sulfate and evaporated to dryness. Recrystallization from methanol gave the product as a white solid (8.42 g, 67\%), mp 92$93{ }^{\circ} \mathrm{C} .{ }^{1} \mathrm{H}$ NMR $\left(\mathrm{CDCl}_{3}\right) \delta: 7.90(\mathrm{~d}, J=9.0 \mathrm{~Hz}, 2 \mathrm{H}), 7.23-7.37(\mathrm{~m}, 5 \mathrm{H}), 6.91(\mathrm{~d}, J=9.0$ $\mathrm{Hz}, 2 \mathrm{H}), 4.65-4.87(\mathrm{~m}, 2 \mathrm{H}), 4.10-4.25(\mathrm{~m}, 1 \mathrm{H}), 3.86(\mathrm{~s}, 3 \mathrm{H}), 3.31-3.46(\mathrm{~m}, 2 \mathrm{H}) .{ }^{13} \mathrm{C}$ $\operatorname{NMR}\left(\mathrm{CDCl}_{3}\right) \delta: 196.0,164.1,139.5,130.6,129.7,129.3,128.0,127.7,114.1,79.8$ 55.7, 41.1, 39.7. IR ( $\mathrm{KBr}$ disc) $\mathrm{cm}^{-1}$ : 1668. EI-MS: $\mathrm{m} / \mathrm{z}$ 300.0. Anal. Calcd for $\mathrm{C}_{17} \mathrm{H}_{17} \mathrm{NO}_{4}: \mathrm{C}, 68.21 ; \mathrm{H}, 5.72 ; \mathrm{N}, 4.68$. Found $\mathrm{C}, 68.17 ; \mathrm{H}, 5.80 ; \mathrm{N}, 4.57$.

3-(4-Methoxy-phenyl)-4-nitro-1-phenyl-butan-1-one (15c). 1-(4-Methoxy-phenyl)-3phenyl-propenone 14c (4.0 g, $16.8 \mathrm{mmol})$, nitromethane $(5.12 \mathrm{~g}, 83.9 \mathrm{mmol})$ and diethylamine $(6.14 \mathrm{~g}, 83.9 \mathrm{mmol})$ were dissolved in dry methanol $(50 \mathrm{~mL})$ and heated under reflux for $24 \mathrm{~h}$. The solution was cooled, acidified with $1 \mathrm{M} \mathrm{HCl}$ and extracted with $\mathrm{CH}_{2} \mathrm{Cl}_{2}$ (2 $\left.\mathrm{x} \quad 100 \mathrm{~mL}\right)$, dried over sodium sulfate and evaporated to dryness. Recrystallization from diethylether gave the product as a white solid (3.08 g, 61\%), mp 62-63 ${ }^{\circ} \mathrm{C} .{ }^{1} \mathrm{H}$ NMR $\left(\mathrm{CDCl}_{3}\right) \delta: 7.90(\mathrm{~d}, J=8.2 \mathrm{~Hz}, 2 \mathrm{H}), 7.54-7.59(\mathrm{~m}, 1 \mathrm{H}), 7.42-7.47$ (m, 2H), 7.18-7.21 (m, 2H), $6.85(\mathrm{~d}, J=8.2 \mathrm{~Hz}, 2 \mathrm{H}), 4.60-4.82(\mathrm{~m}, 2 \mathrm{H}), 4.12-4.20(\mathrm{~m}$, 
1H), $3.76(\mathrm{~s}, 3 \mathrm{H}), 3.44-3.51(\mathrm{~m}, 2 \mathrm{H}) .{ }^{13} \mathrm{C} \mathrm{NMR}\left(\mathrm{CDCl}_{3}\right) \delta: 197.0,159.1,136.5,133.6$, $131.0,128.8,128.5,128.0,114.5,79.9,55.3,41.7,38.7 . \mathrm{IR}(\mathrm{KBr}$ disc $) \mathrm{cm}^{-1}: 1684$. EIMS: m/z 299. Anal. Calcd for $\mathrm{C}_{17} \mathrm{H}_{17} \mathrm{NO}_{4}: \mathrm{C}, 68.21 ; \mathrm{H}, 5.72 ; \mathrm{N}, 4$ 4.62. Found $\mathrm{C}, 68.08 ; \mathrm{H}$, $5.71 ; \mathrm{N}, 4.62$.

3-(4-Bromo-phenyl)-4-nitro-1-phenyl-butan-1-one (15d). 3-(4-Bromo-phenyl)-1phenyl-propenone 14d $(6.80 \mathrm{~g}, 23.7 \mathrm{mmol})$, nitromethane $(7.22 \mathrm{~g}, 118 \mathrm{mmol})$ and diethylamine $(8.66 \mathrm{~g}, 118 \mathrm{mmol})$ were dissolved in dry methanol $(200 \mathrm{~mL})$ and heated under reflux for $24 \mathrm{~h}$. The solution was cooled, acidified with $1 \mathrm{M} \mathrm{HCl}$ and the resulting precipitate was isolated by filtration. Recrystallization from methanol gave the product as a white solid (4.91 g, 60\%), mp 90-91 ${ }^{\circ} \mathrm{C} .{ }^{1} \mathrm{H}$ NMR $\left(\mathrm{CDCl}_{3}\right) \delta: 7.90(\mathrm{~d}, J=7.2,2 \mathrm{H})$, 7.55-7.61 (m, 1H), 7.41-7.48 (m, 4H), 7.14-7.20 (m, 2H), 4.62-4.84 (m, 2H), 4.15-4.25 (m, 1H), 3.35-3.50 (m, 2H). ${ }^{13} \mathrm{C}$ NMR $\left(\mathrm{CDCl}_{3}\right) \delta: 196.7,138.4,136.4,134.0,132.4$, 129.5, 129.0, 128.2, 122.1, 79.5, 41.5, 39.0. IR (KBr disc) $\mathrm{cm}^{-1}: 1683$. EI-MS: m/z 348 . Anal. Calcd for $\mathrm{C}_{16} \mathrm{H}_{14} \mathrm{BrNO}_{3}: \mathrm{C}, 55.19 ; \mathrm{H}, 4.05 ; \mathrm{Br}, 22.95 ; \mathrm{N}$, 4.02. Found C, 54.97; H, 4.09; $\mathrm{Br}, 23.21 ; \mathrm{N}, 3.91$.

Photosensitizer Formulation. Photosensitizer $\left(1.3 \times 10^{-5} \mathrm{~mol}\right)$ was dissolved in $2.0 \mathrm{~mL}$ of dry THF. A pre-prepared mixture of CrEL / 1,2-propanediol (10:3 v/v) $(0.2 \mathrm{~mL})$ was added to the solution and placed in a sonic bath, under $\mathrm{N}_{2}$, for $1 \mathrm{~h}$. The THF was removed under reduced pressure and the remaining mixture was slowly dissolved in phosphate buffered saline (PBS) solution $(15 \mathrm{~mL})$. This solution was then passed through an Acrodisc $25 \mathrm{~mm}$ syringe filter (with $0.2 \mu \mathrm{m}$ HT Tuffryn membrane) and transferred to a 
volumetric flask where the solution was made up to $25 \mathrm{~mL}$ with PBS solution. Dilutions into Minimum Essential Medium (MEM) containing 10\% (v/v) foetal calf serum (FCS) were used for assaying. The quantity of CrEL / 1,2-propanediol in a photosensitizer solution was always less than $0.03 \%$.

Cell Culture. HeLa cervical carcinoma cells and MRC5-SV40 transformed fibroblasts cultures were cultured in MEM supplemented with $10 \%(\mathrm{v} / \mathrm{v})$ FCS, $1 \%(\mathrm{v} / \mathrm{v})$ nonessential amino acids, $2 \mu \mathrm{g} / \mathrm{ml}$ fungizone (amphotericin B), 50 unit / $\mathrm{ml}$ penicillin, $50 \mu \mathrm{g}$ / $\mathrm{ml}$ streptomycin, $20 \mathrm{mM}$ HEPES and 1\% (v/v) L-Glutamine (GIBCO-BRL) and maintained in $5 \% \mathrm{CO}_{2}(\mathrm{v} / \mathrm{v})$ at $37^{\circ} \mathrm{C}$. Cells were routinely cultured for at least 2 passages before use in the cytotoxicity / fluorescence assays.

Fluorescence Microscopy. HeLa cells were seeded at 30,000 cells / well in chamber slides and allowed to adhere for $24 \mathrm{~h} . \mathbf{1 8 a}\left(1 \times 10^{-5} \mathrm{M}\right)$ was added to each chamber and incubated at $37{ }^{\circ} \mathrm{C}$ in the dark for $1 \mathrm{~h}$, following which the cells were washed 4 times with media. The cells were treated with fixative solution ( $3.7 \%$ formaldehyde) for $15 \mathrm{~min}$ at $37^{\circ} \mathrm{C}$ after which the cells were washed twice with PBS. Mounting fluid and a cover slip were then placed on each slide. The slides were viewed using an Axio Zeiss fluorescent microscope equipped with a rhodamine filter.

Confocal Laser Scanning Microscopy. HeLa cells were incubated in the dark at $37^{\circ} \mathrm{C}$ with $1 \times 10^{-5} \mathrm{M} \mathrm{18a}$ for $1 \mathrm{~h}$ in chamber slides, rinsed in medium 4 times and fixed with $3.7 \%$ formaldehyde for $15 \mathrm{~min}$ at $37^{\circ} \mathrm{C}$, after which the cells were washed twice with 
PBS. For contrast imaging, the cell nuclei were then stained with SYTOX green $(50 \mathrm{nM})$ for 15 min, following which the cells were washed twice with deionised water and PBS. Mounting fluid and a cover slip were then placed on each slide. Image analysis was accomplished using the Leica TCS SL Confocal Laser Scanning Microscope fitted with spectrophotometers for emission band wavelength selection and an oil immersion lens (63 x 1.32 numerical aperture). 3-D reconstructions of $\mathbf{1 8 a}$ distribution were performed following collection of 20 focal plane sections 0.5 to $1 \mu \mathrm{m}$ apart, which were combined as X-y projection images. Nuclear fluorescent probe (SYTOX green) and cell-bound 18a were excited by a $50 \mathrm{~mW}$ argon laser with a $488 \mathrm{~nm}$ line and a $1 \mathrm{~mW}$ green $\mathrm{HeNe} 543$ $\mathrm{nm}$ laser, respectively. The emission peaks of cell-bound SYTOX green and 18a were 523 and $683 \mathrm{~nm}$, respectively. For simultaneous detection of cell-bound 18a and the nuclear probe SYTOX green, a 640-730 nm band-pass filter was used in channel 1 (red) for 18a, and a 505-550 nm band-pass filter in channel 2 (green) for SYTOX green. All parameters were kept constant to ensure reliable comparison throughout the experiment.

Cytotoxicity Studies of 1 . Stock DMSO solutions of 1 were diluted with MEM containing 10\% FCS. Cells were seeded at 5,000 cells / well in 96-well plates and incubated for $24 \mathrm{~h}$. Cells were incubated with varying concentrations of 1 in the dark for $24 \mathrm{~h}$ at $37^{\circ} \mathrm{C}$. The culture medium was removed, the cells were washed three times with PBS and fresh culture medium was added to each well. The plates were irradiated with a light dose of either 8 or $16 \mathrm{~J} \mathrm{~cm}^{-2}$ from a filtered light source (wavelength $600-750 \mathrm{~nm}$ ). Following irradiation, the cells were incubated for a further $48 \mathrm{~h}$ before being assessed for cell survival. The dark toxicity was also assessed in every experiment. Each assay was carried out in triplicate and results presented as an average. 
Measurement of Cell Viability. Cell viability was estimated using the tetrazolium chlorimetric reduction assay (MTT assay). The MTT solution was added to the cells at a final concentration of $0.5 \mathrm{mg} / \mathrm{ml}$ and incubated for $3 \mathrm{~h}$ at $37^{\circ} \mathrm{C}$. The MTT solution was then removed and $100 \mu \mathrm{L}$ DMSO was added to each well in order to lyse the cells and release the formazan dye. After $1 \mathrm{~h}$ the plates were read using a VICTOR 1420 multilabel HTS plate reader at $540 \mathrm{~nm}$. All results are presented as the mean \pm SEM from three independent experiments and each sample measured in quadruplicate.

\section{References}

1. O'Shea, D.F.; Miller, M.A.; Matsueda, H.; Lindsey, J.S. Inorg. Chem. 1996, 35, 7325. 
UV-Visible Spectra

16a Chloroform

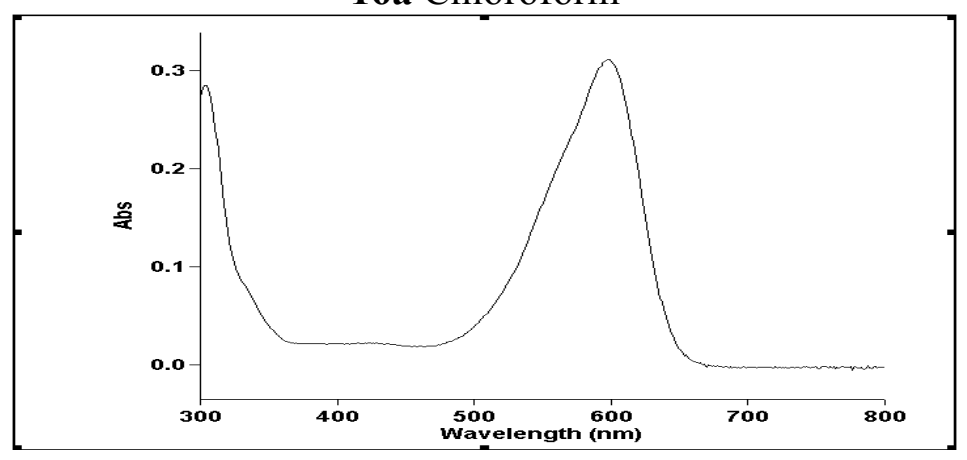

16b Chloroform

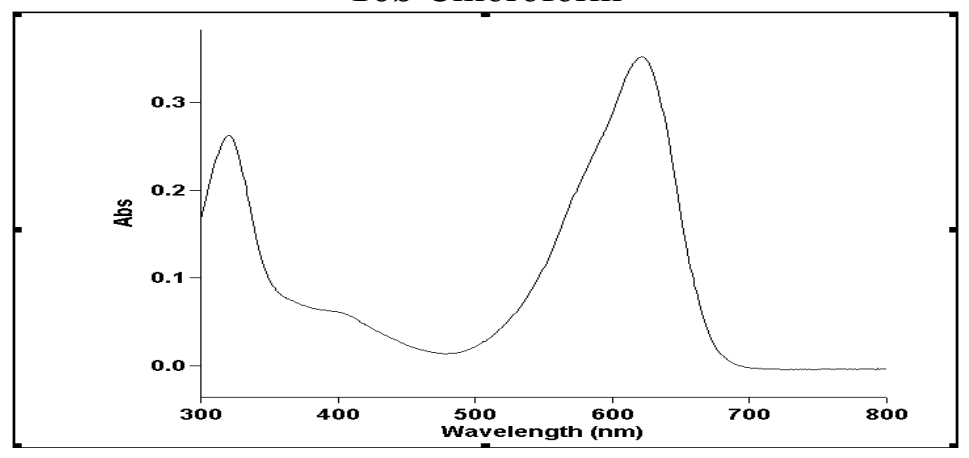

16c Chloroform

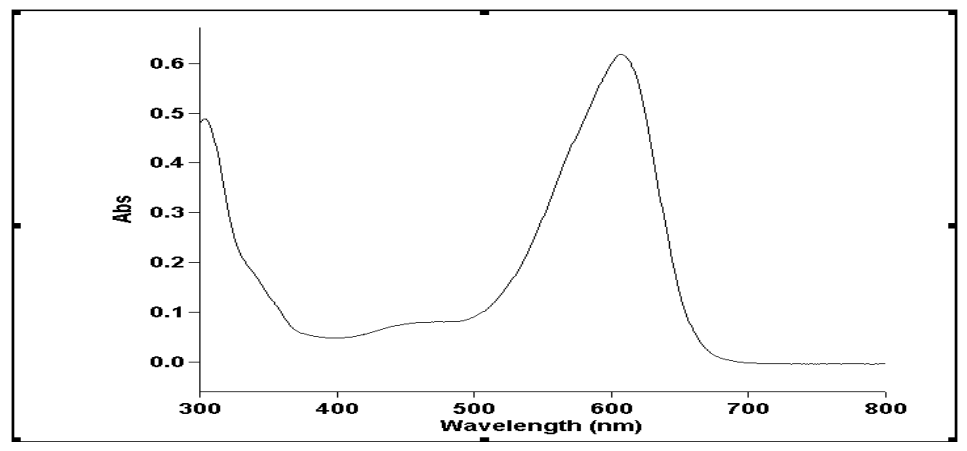

16d Chloroform

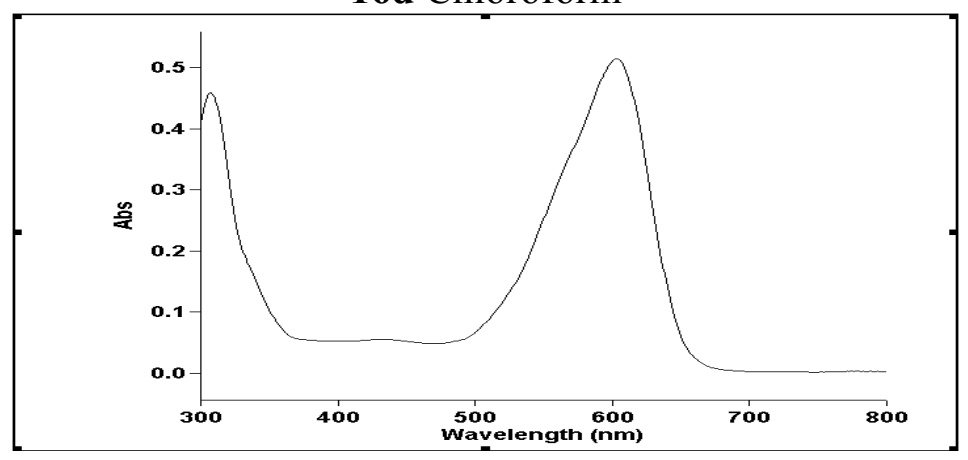

S8 
17a Chloroform

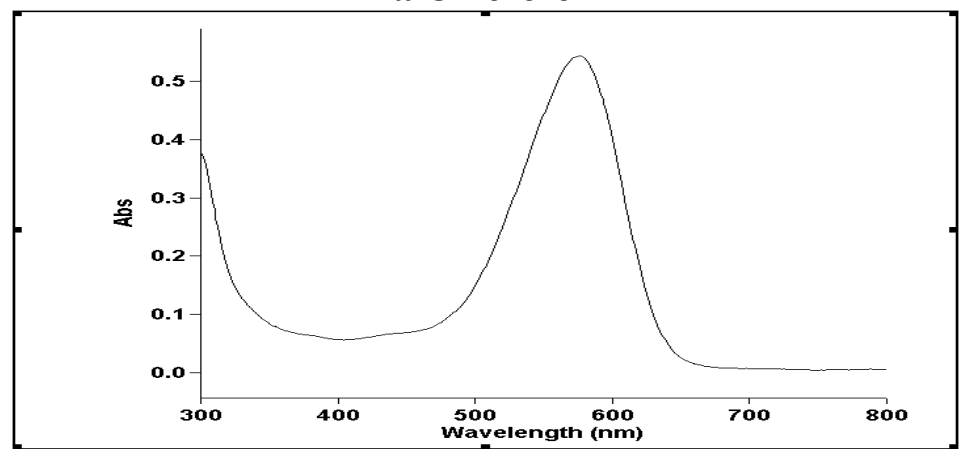

17b Chloroform

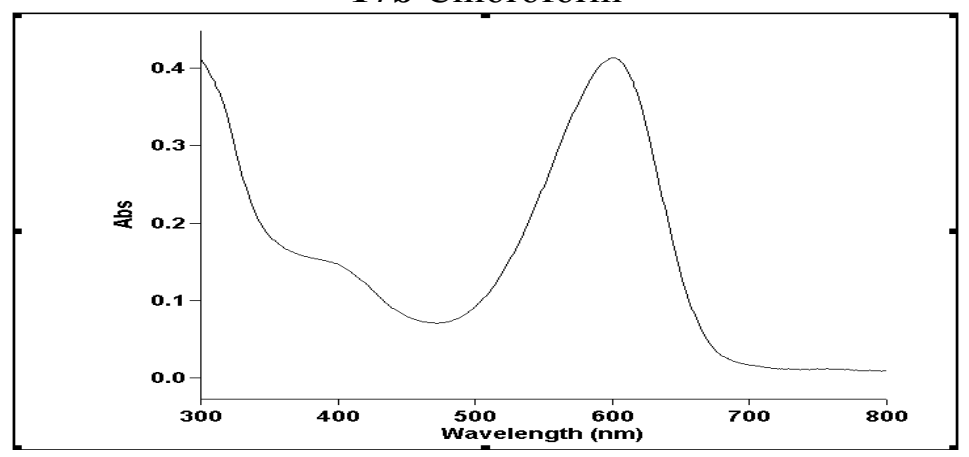

17c Chloroform

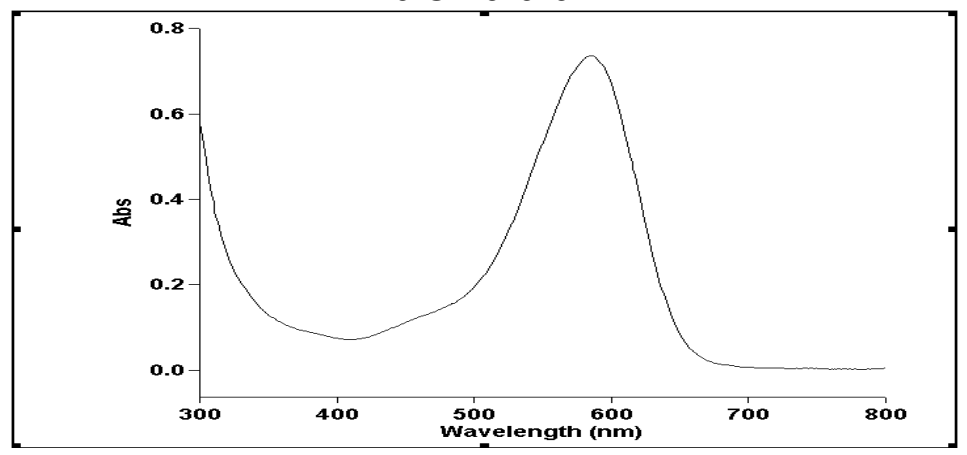

S9 
18a Water / Cremophor EL

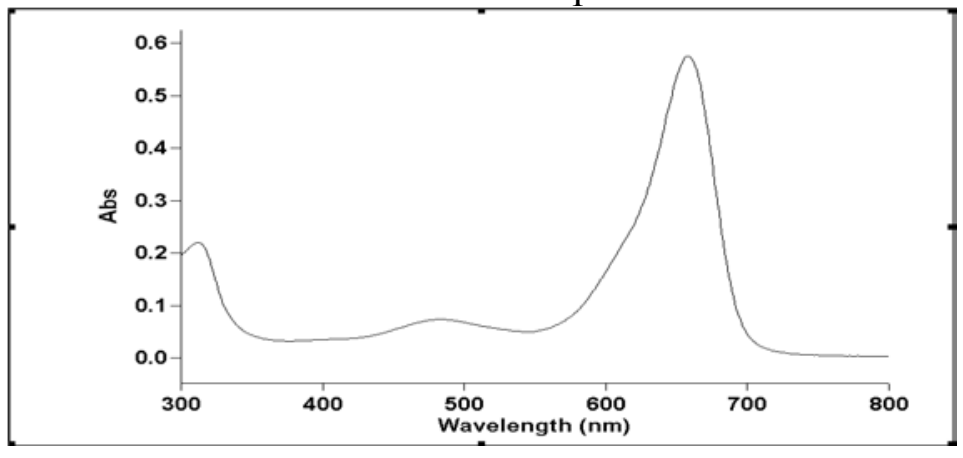

18a Ethanol

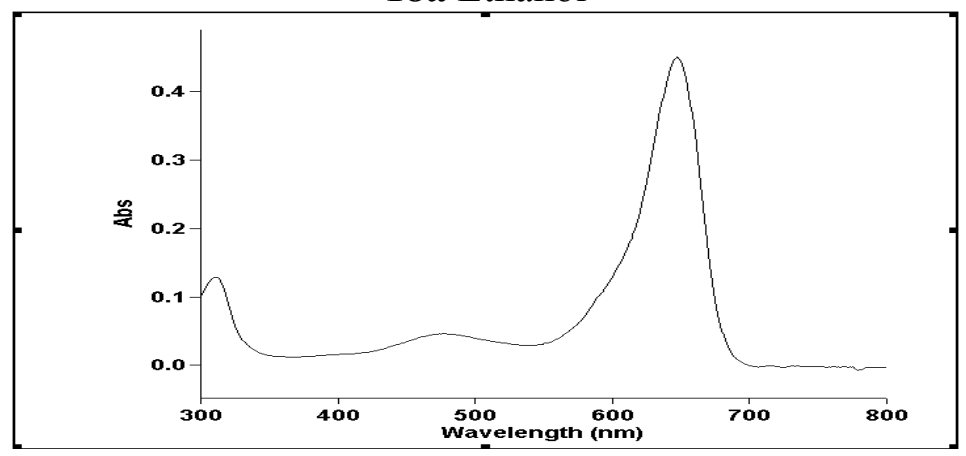

18a Toluene

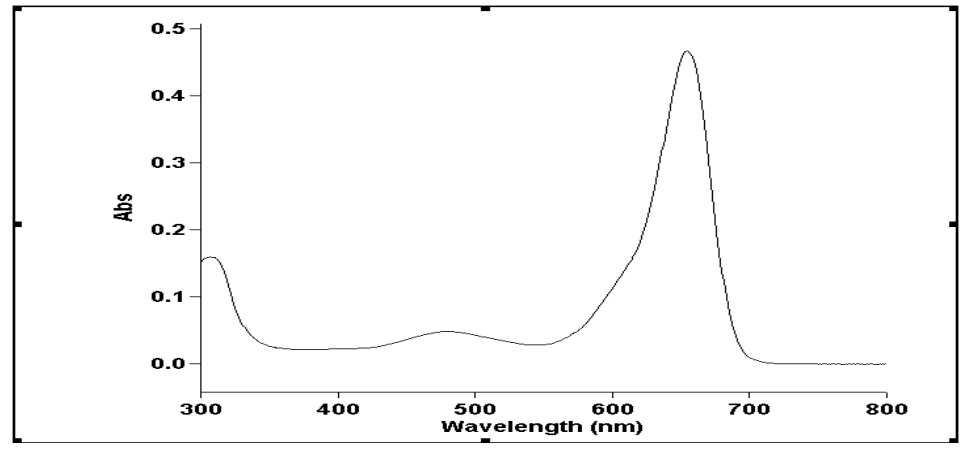


18b Water / Cremophor EL

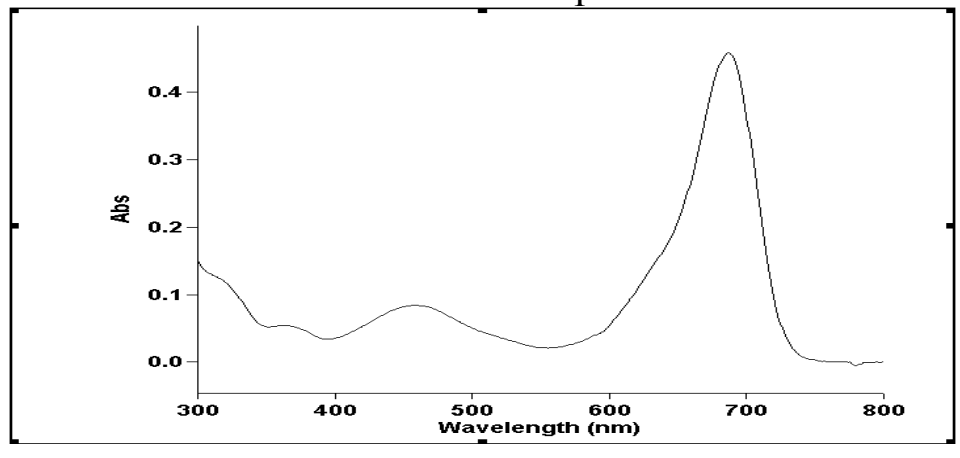

18b Ethanol

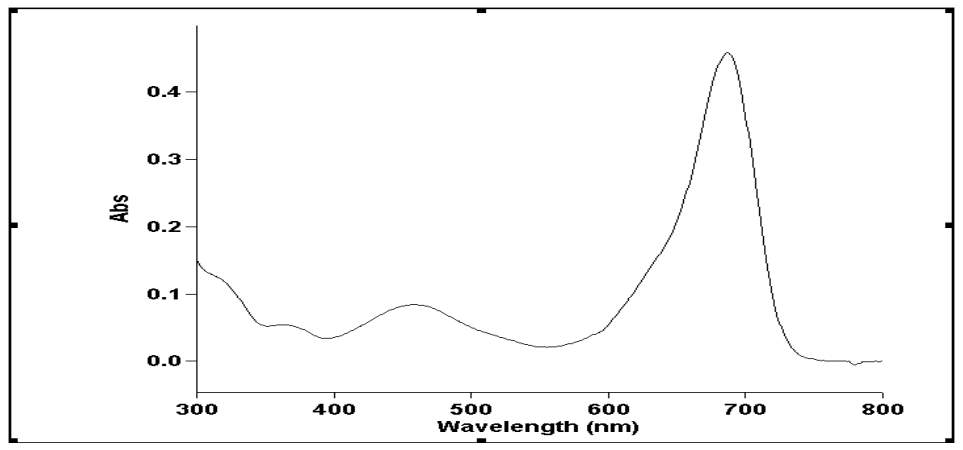

18b Toluene

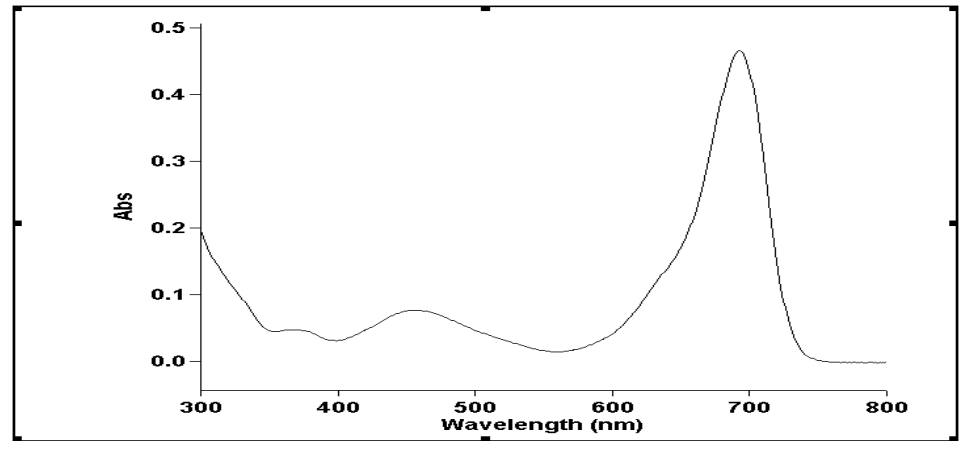


18c Water / Cremophor EL

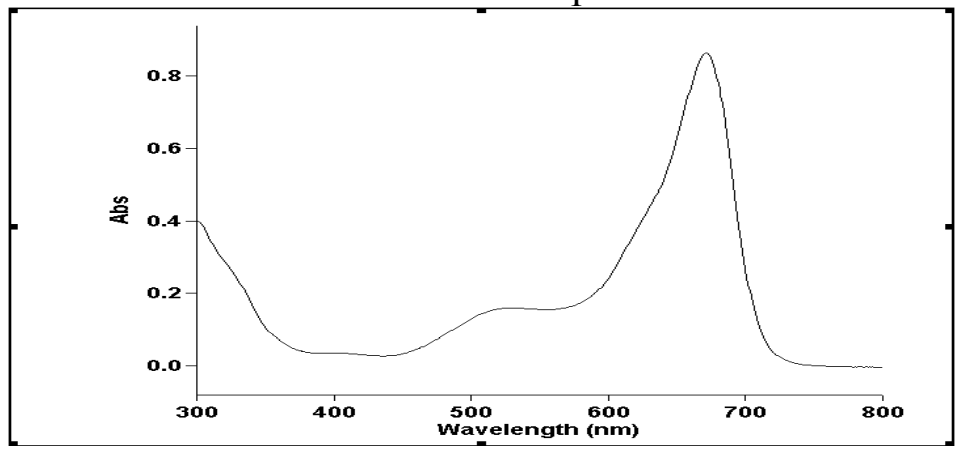

18c Ethanol

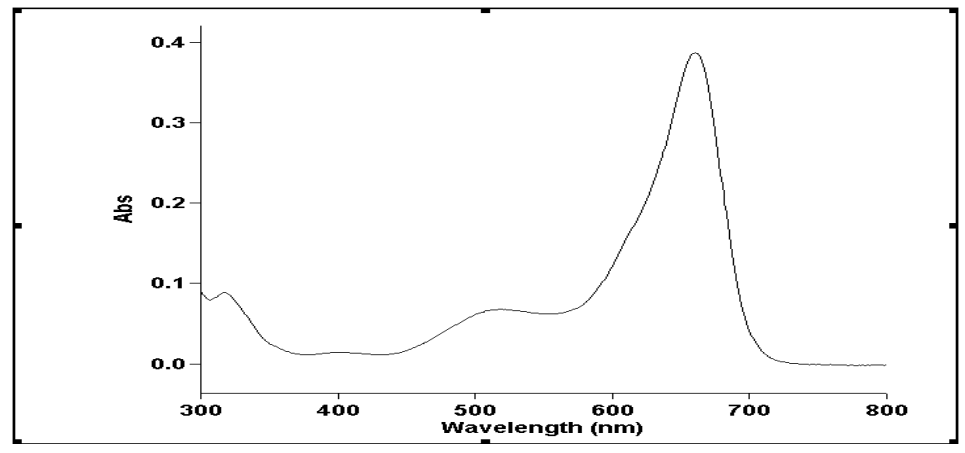

18c Toluene

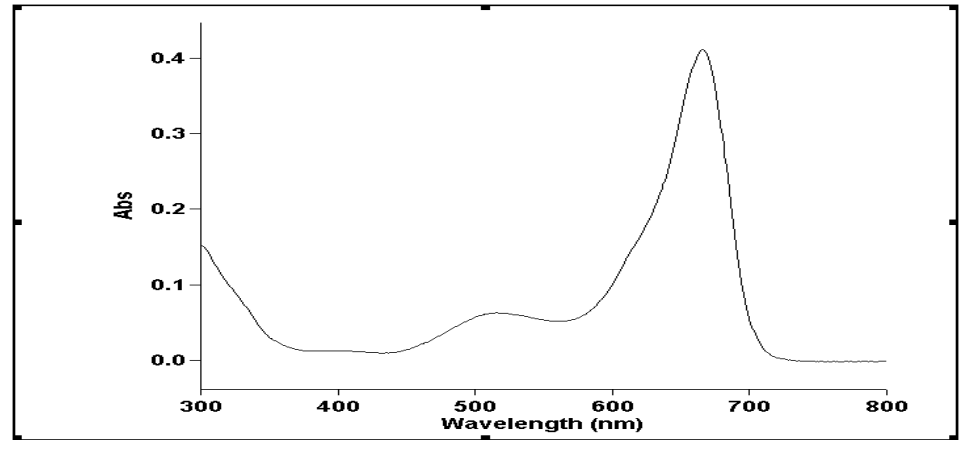


18d Water / Cremophor EL

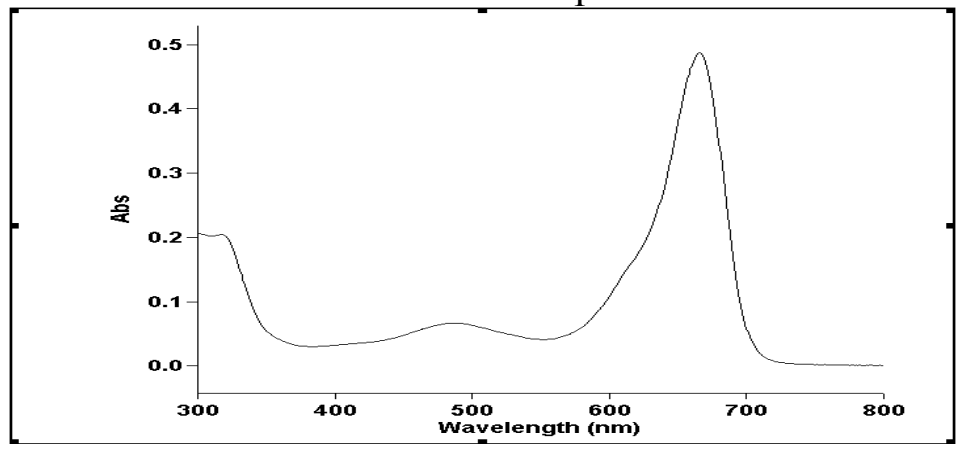

18d Ethanol

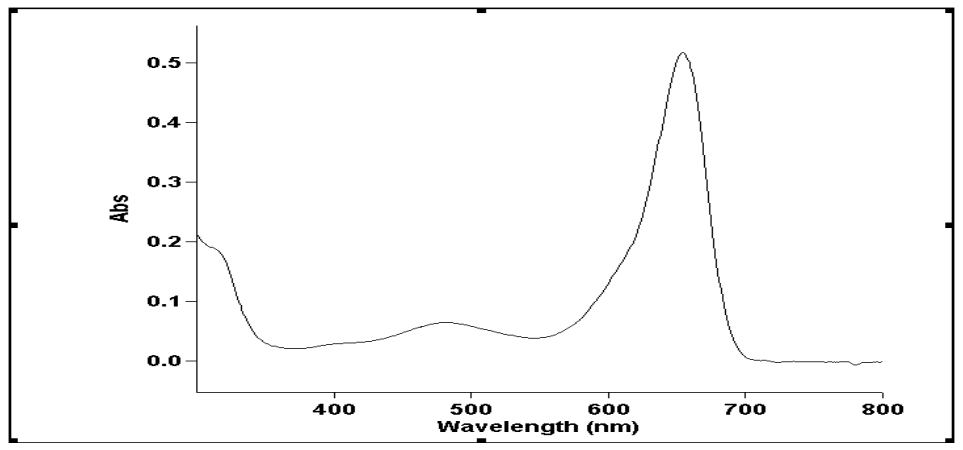

18d Toluene

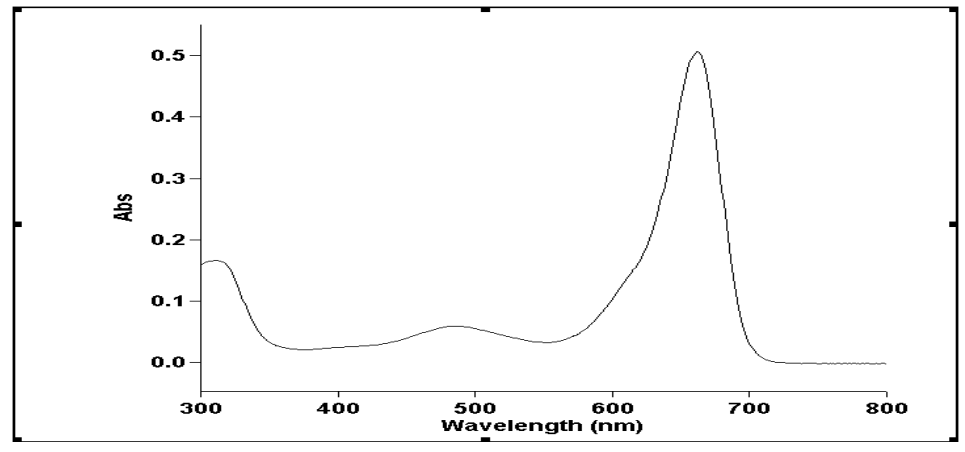


19a Water / Cremophor EL

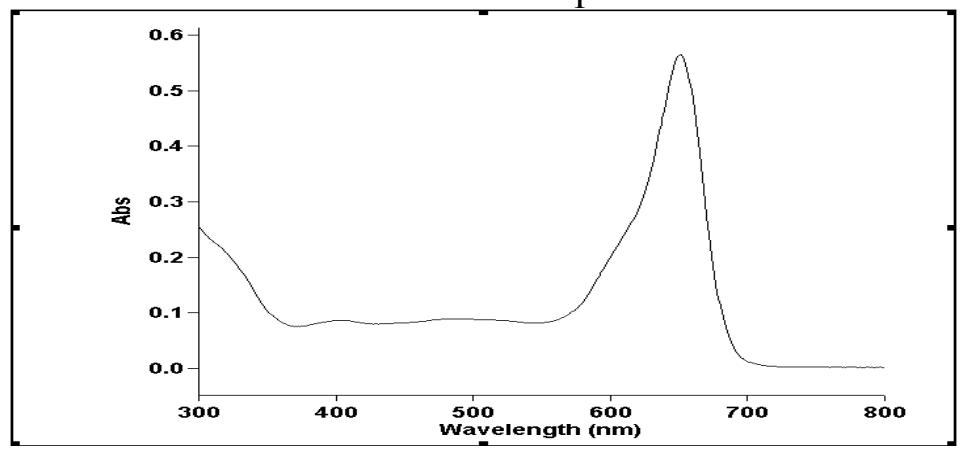

19a Ethanol

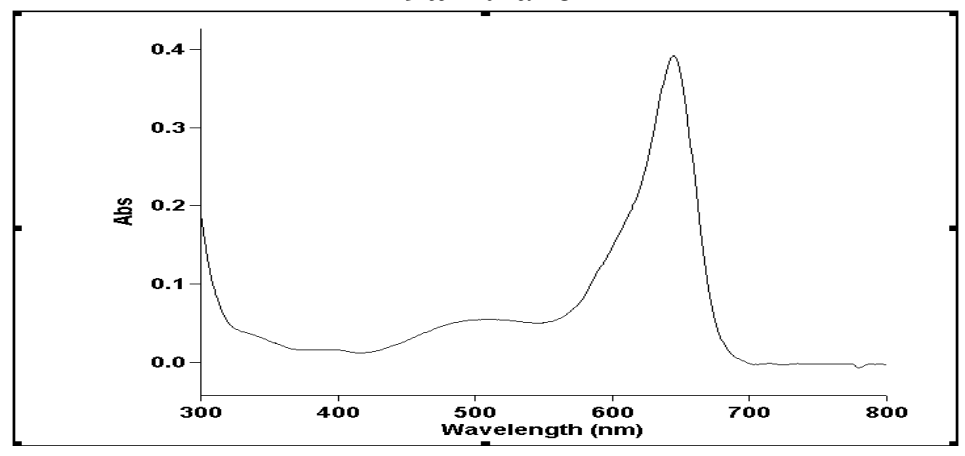

19a Toluene

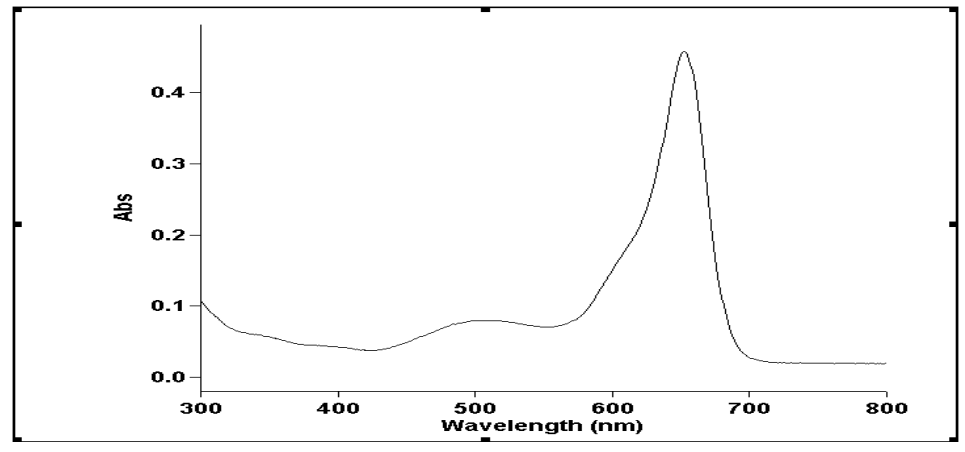


19b Water / Cremophor EL

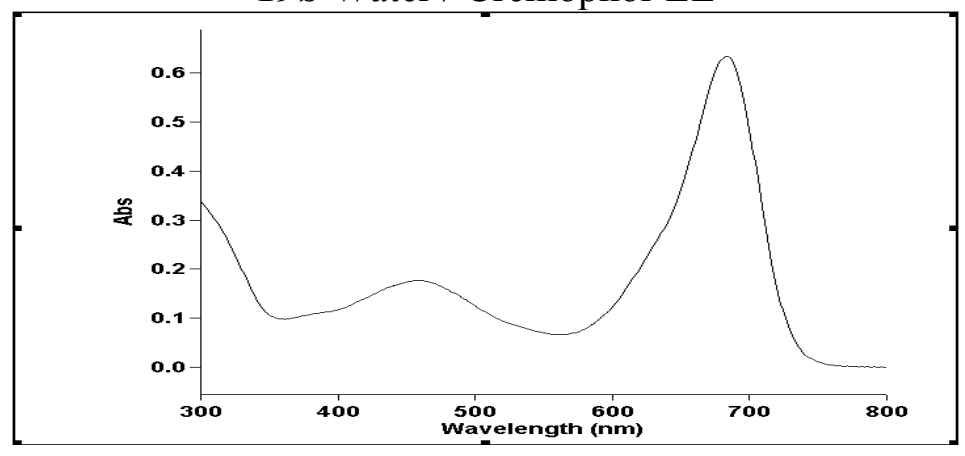

19b Ethanol

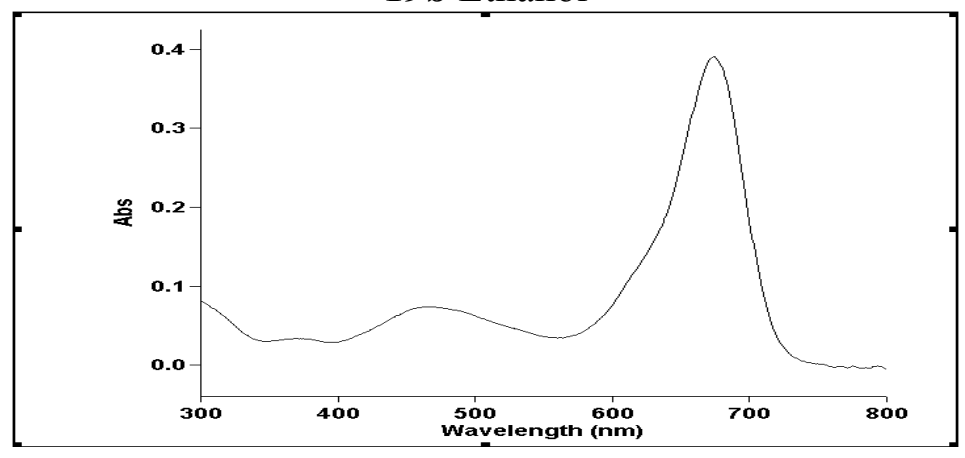

19b Toluene

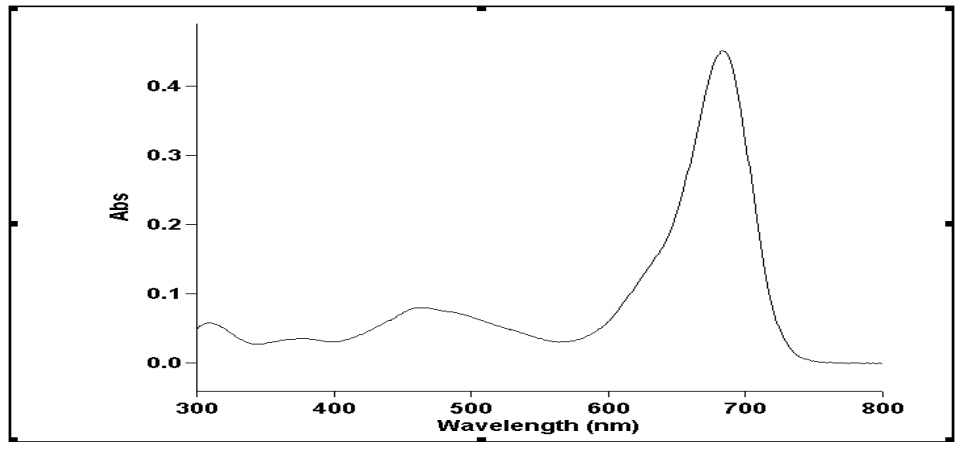


19c Water / Cremophor EL

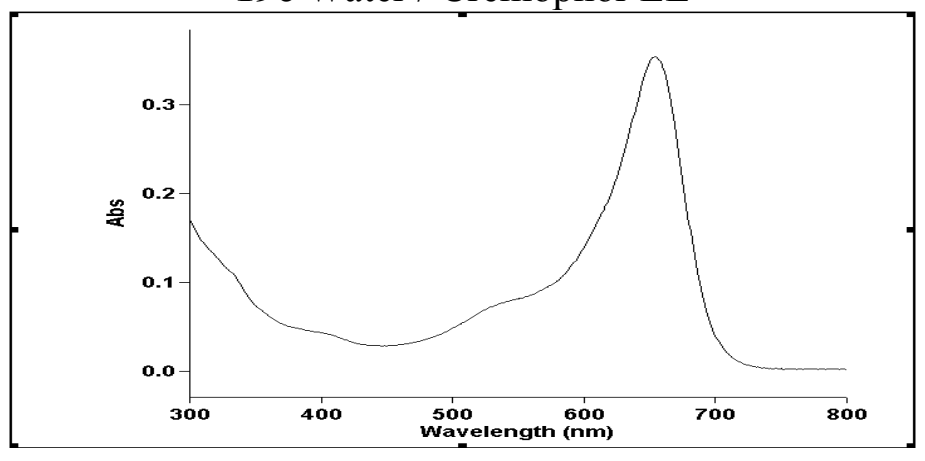

19c Ethanol

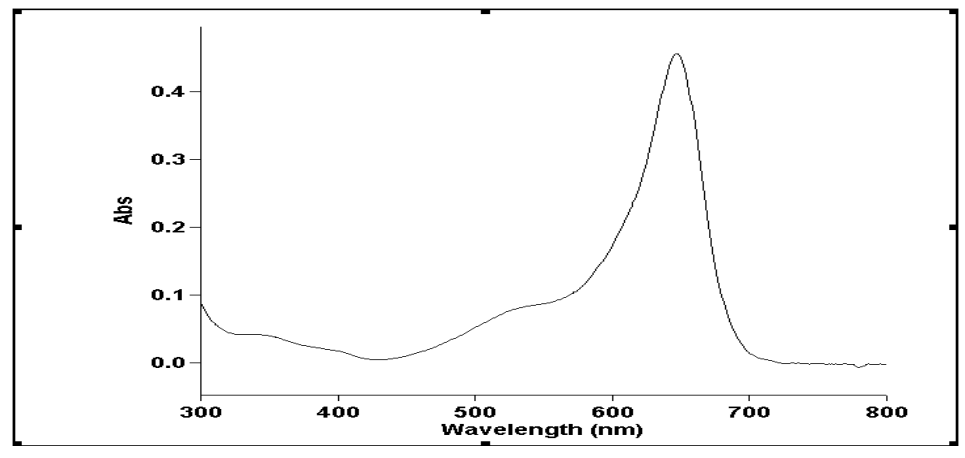

19c Toluene

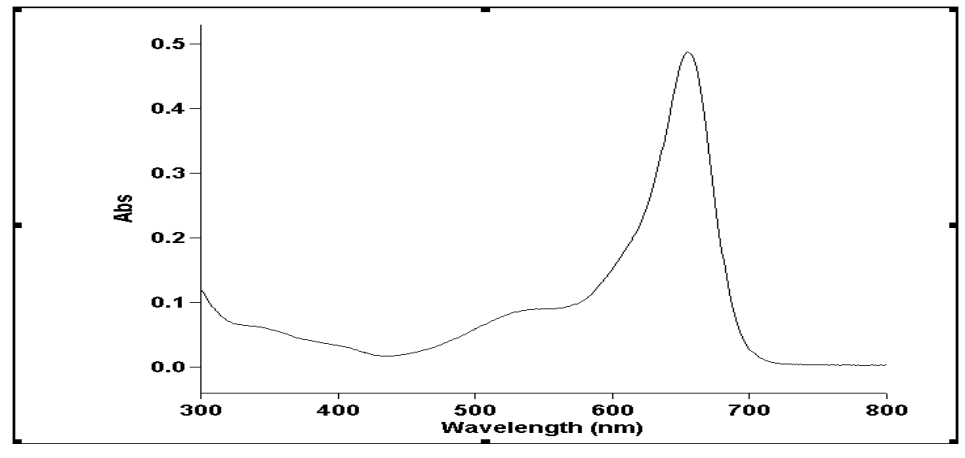




\section{Fluorescence Spectra}

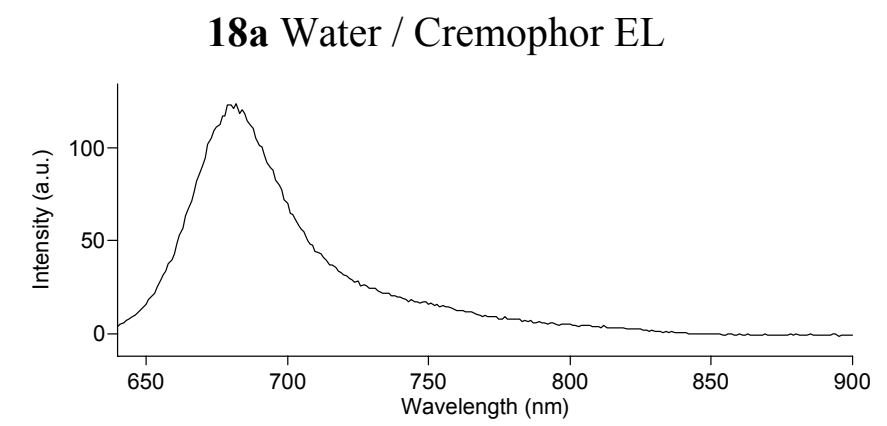

18a Ethanol

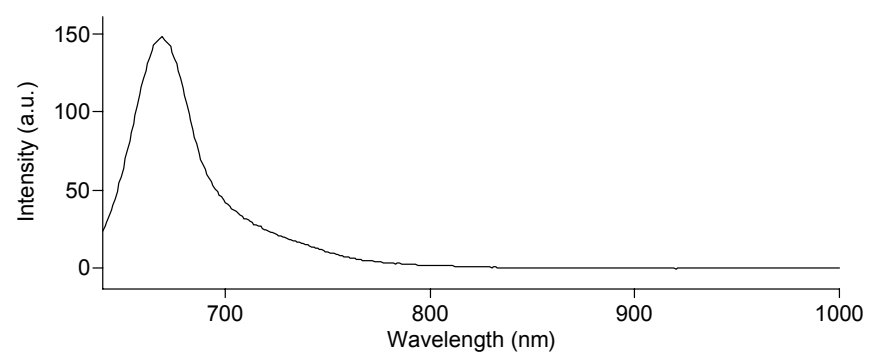

18a Toluene

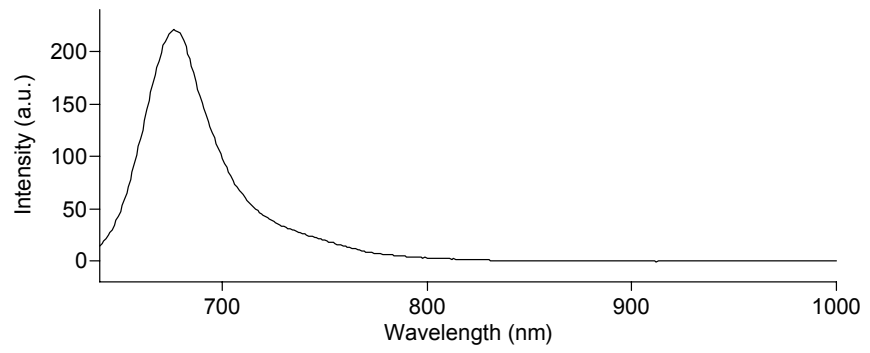


18b Water / Cremophor EL

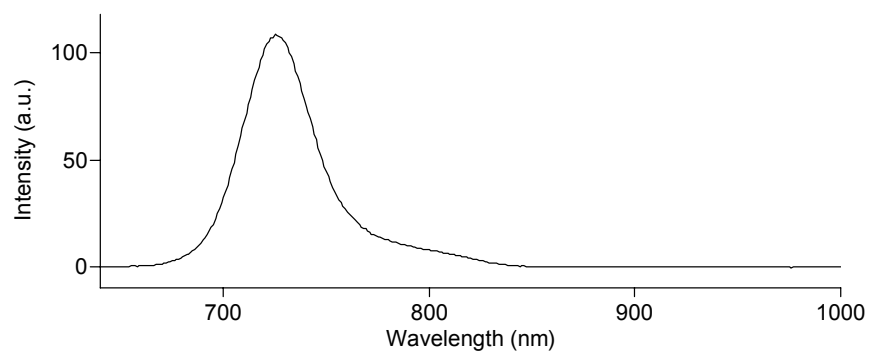

18b Ethanol

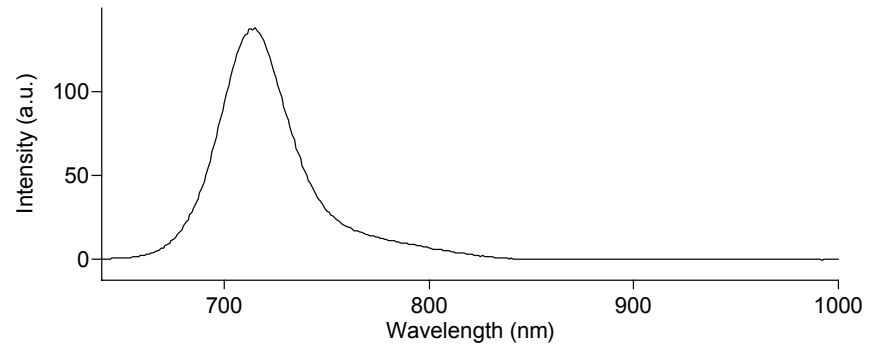

18b Toluene

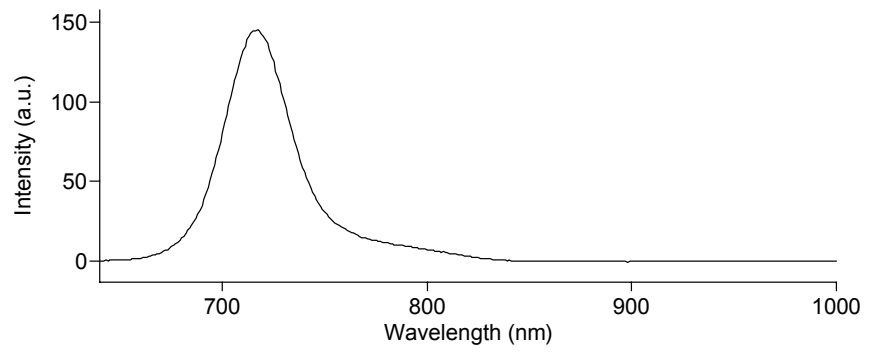


18c Water / Cremophor EL

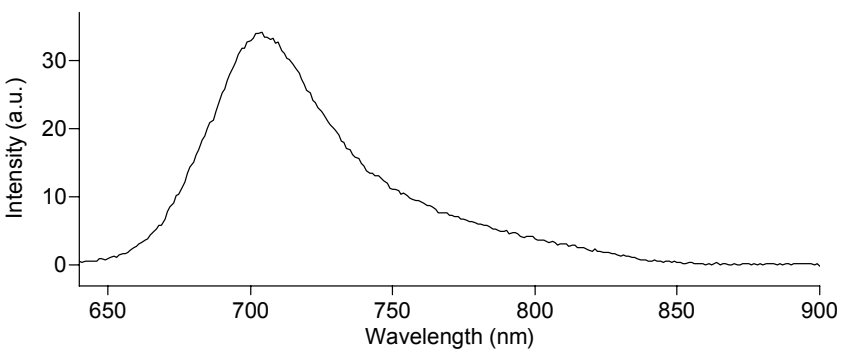

18c Ethanol

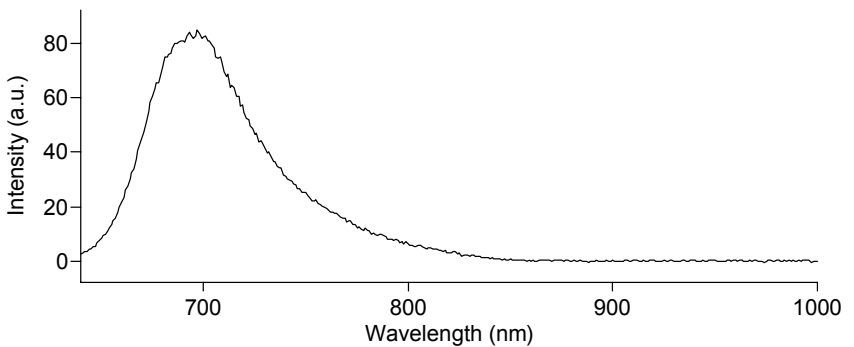

18c Toluene

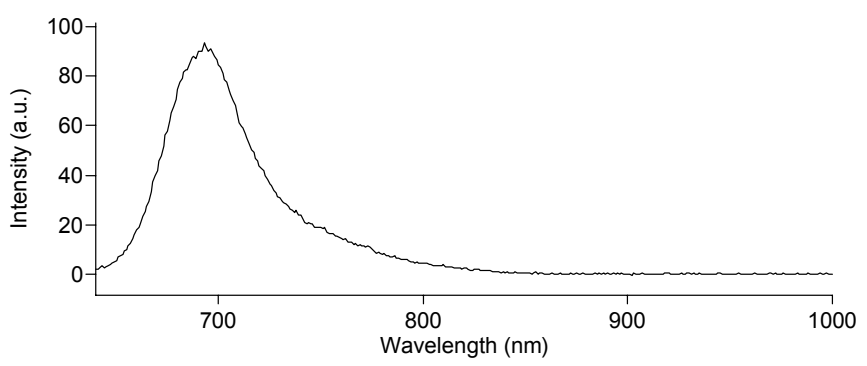




\section{8d Water / Cremophor EL}

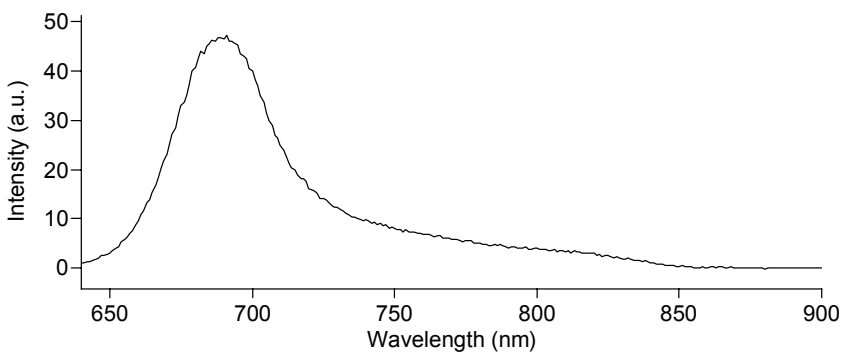

18d Ethanol

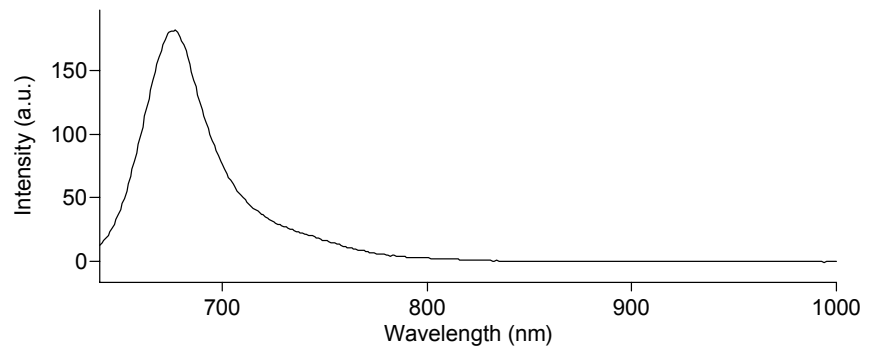

18d Toluene

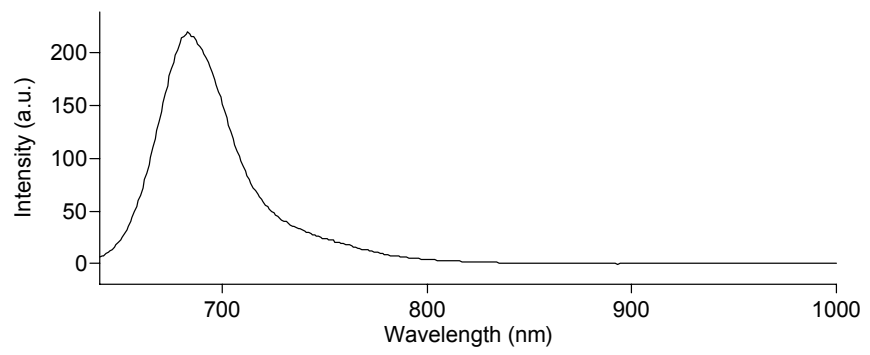


19a Water / Cremophor EL

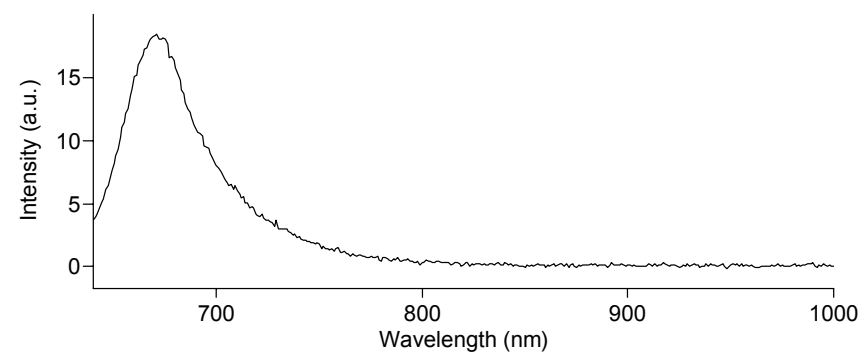

19a Ethanol

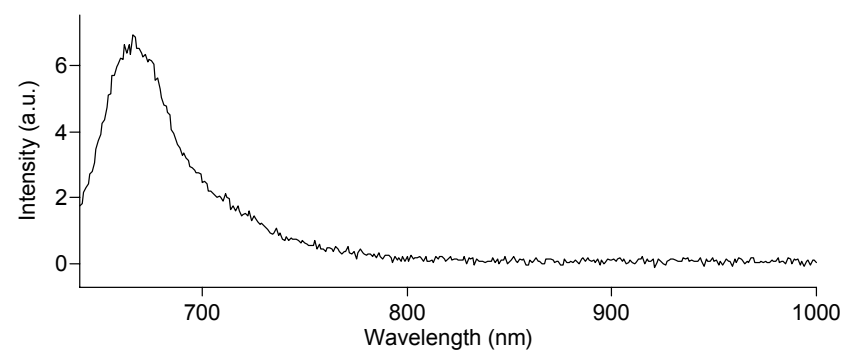

19a Toluene

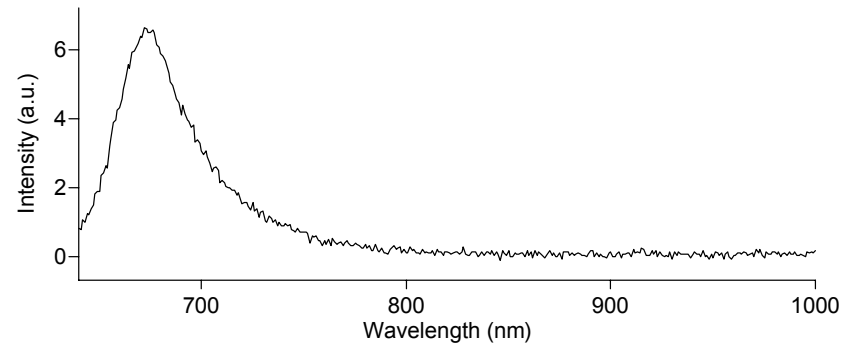


19b Water / Cremophor EL

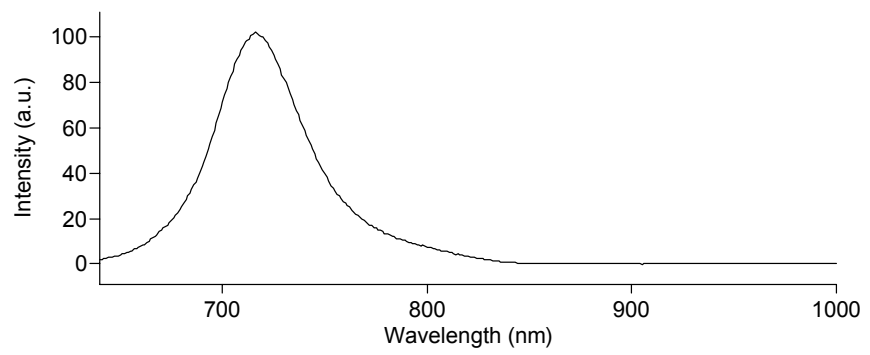

19b Ethanol

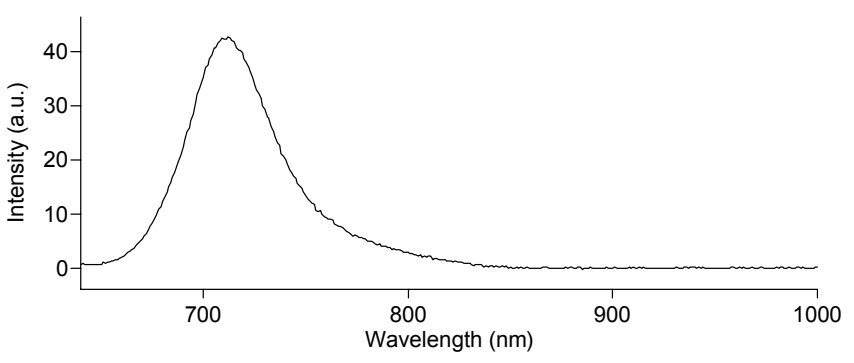

19b Toluene

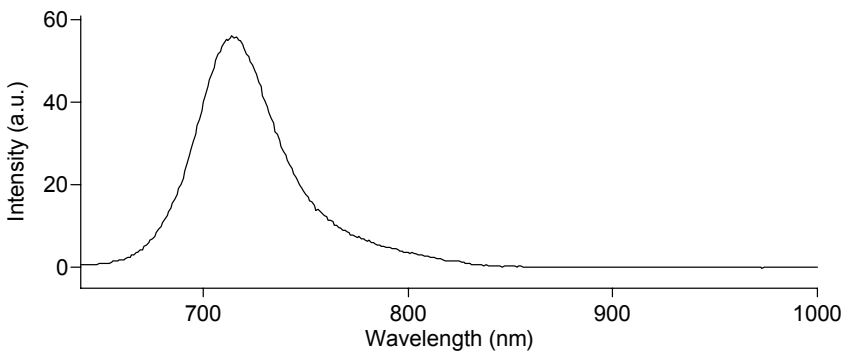




\section{9c Water / Cremophor EL}

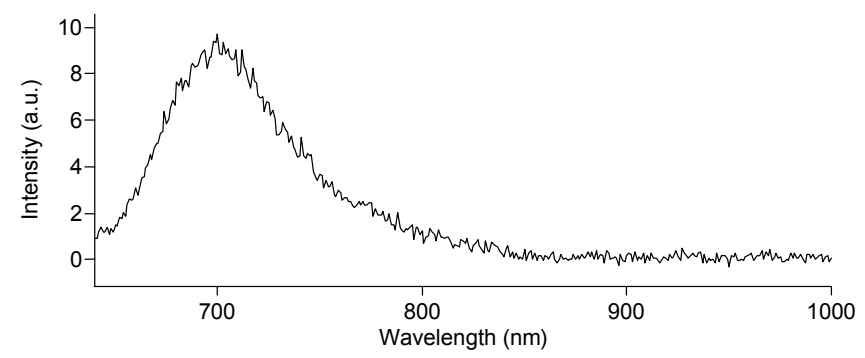

19c Ethanol

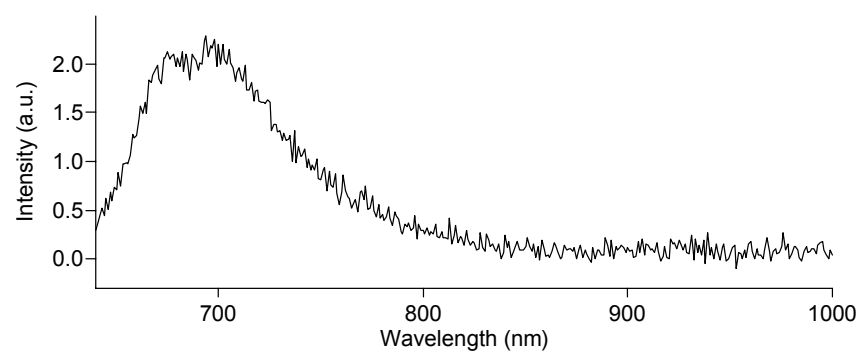

19c Toluene

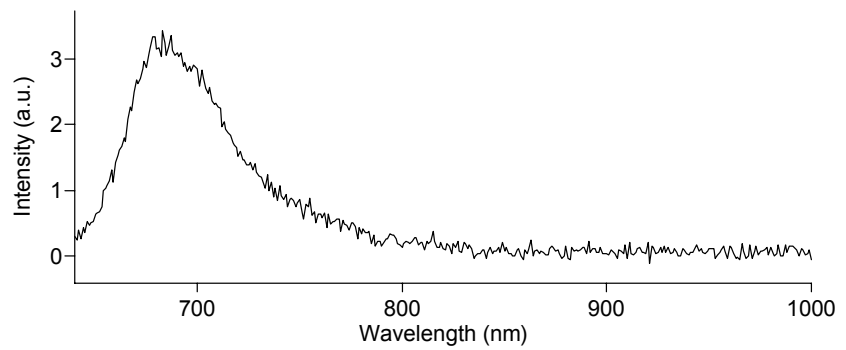




\section{X-Ray Structure Data for 19a}

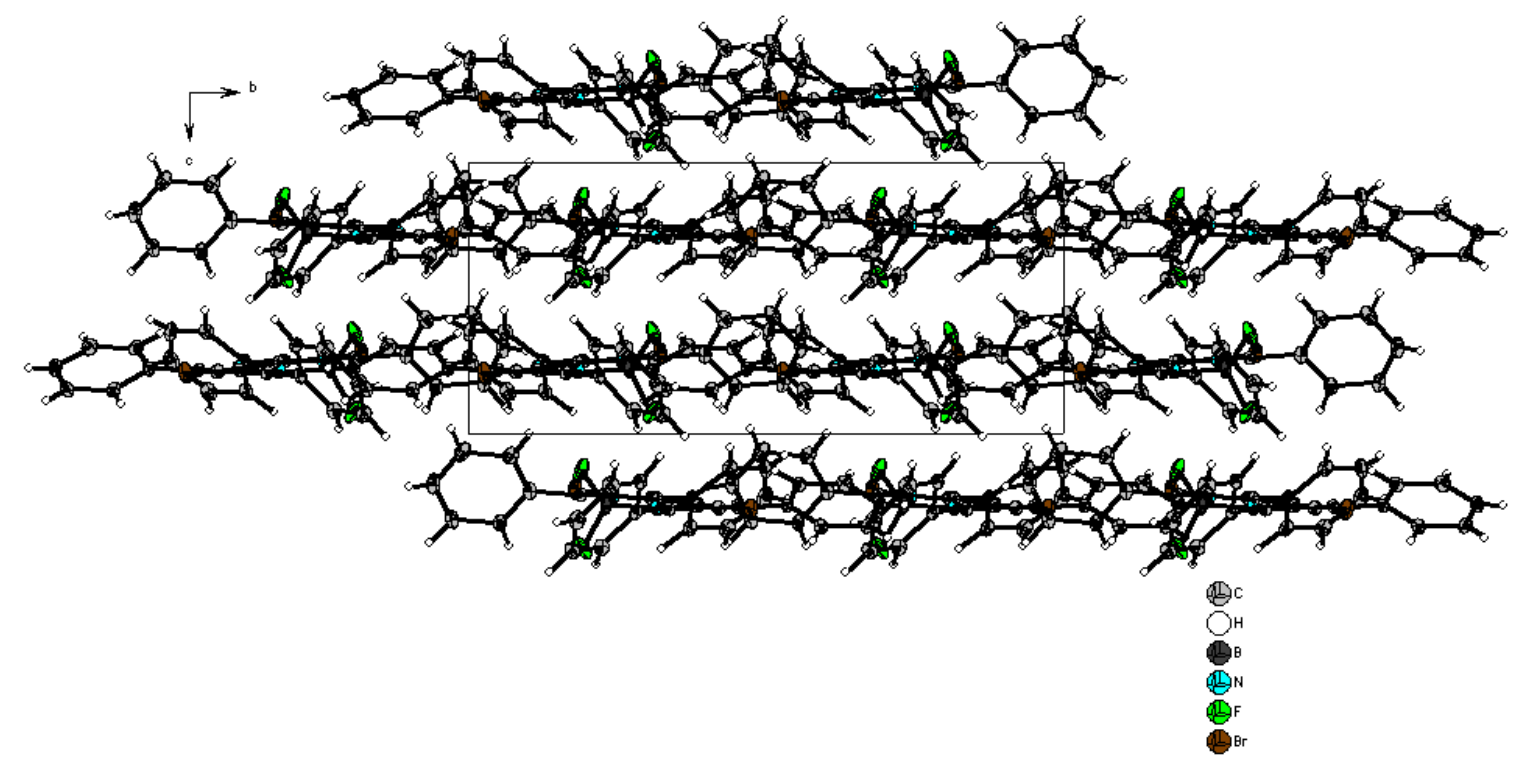

19a, view along $\left[\begin{array}{lll}1 & 0 & 0\end{array}\right]$; thermal ellipsoids are drawn on the $50 \%$ probability level 
Table 1. Crystal data and structure refinement for 19a.

$\begin{array}{ll}\text { Identification code } & \mathbf{1 9 a} \\ \text { Empirical formula } & \mathrm{C}_{32} \mathrm{H}_{20} \mathrm{~B} \mathrm{~N}_{3} \mathrm{~F}_{2} \mathrm{Br}_{2} \\ \text { Formula weight } & 655.14 \\ \text { Temperature } & 100(2) \mathrm{K} \\ \text { Wavelength } & 0.71073 \AA \\ \text { Crystal system } & \text { Monoclinic } \\ \text { Space group } & \mathrm{Cc}(\# 9) \\ \text { Unit cell dimensions } & \mathrm{a}=19.7763(16) \AA \quad \alpha=90^{\circ} . \\ & \mathrm{b}=17.0482(14) \AA \\ & \mathrm{c}=8.2902(7) \AA \\ \text { Volume } & 2624.6(4) \AA^{3} \\ \text { Z } & 4 \\ \text { Density (calculated) } & 1.658 \mathrm{Mg} / \mathrm{m}^{3} \\ \text { Absorption coefficient } & 3.132 \mathrm{~mm}{ }^{-1} \\ \text { F(000) } & 1304 \\ \text { Crystal size } & 0.30 \times 100(10)^{\circ} . \\ \text { Theta range for data } & 2.19 \text { to } 28.61^{\circ} . \\ \text { collection } & \\ \text { Index ranges } & \end{array}$


Table 2. Atomic coordinates $\left(\mathrm{x} 10^{4}\right)$ and equivalent isotropic displacement parameters $\left(\AA^{2} \times 10^{3}\right)$

for 19a.

\begin{tabular}{|c|c|c|c|c|}
\hline Atom & $x$ & $\mathrm{y}$ & z & $\mathrm{U}(\mathrm{eq})$ \\
\hline $\mathrm{C}(1)$ & $7851(1)$ & $8173(1)$ & $2356(3)$ & $13(1)$ \\
\hline$C(2)$ & $8567(1)$ & $8086(2)$ & $2307(3)$ & $15(1)$ \\
\hline$C(5)$ & $9054(1)$ & $8734(2)$ & $2330(3)$ & $15(1)$ \\
\hline$C(6)$ & $8802(2)$ & $9377(2)$ & $1221(3)$ & 19(1) \\
\hline$C(7)$ & $9267(2)$ & $9973(2)$ & $1225(4)$ & $23(1)$ \\
\hline$C(8)$ & $9980(2)$ & $9964(2)$ & $2305(4)$ & $26(1)$ \\
\hline$C(9)$ & $10228(2)$ & $9339(2)$ & $3415(4)$ & $21(1)$ \\
\hline$C(10)$ & $9773(1)$ & $8715(2)$ & $3420(3)$ & $17(1)$ \\
\hline$C(3)$ & $8663(1)$ & $7290(2)$ & $2232(3)$ & $15(1)$ \\
\hline $\operatorname{Br}(1)$ & $9469(1)$ & $6789(1)$ & 1987(1) & $20(1)$ \\
\hline$C(4)$ & $8024(1)$ & $6888(2)$ & $2195(3)$ & $14(1)$ \\
\hline$C(11)$ & $7902(1)$ & $6036(2)$ & $2069(3)$ & $16(1)$ \\
\hline$C(12)$ & $7317(1)$ & $5712(2)$ & $768(4)$ & $20(1)$ \\
\hline$C(13)$ & $7231(2)$ & $4905(2)$ & $634(4)$ & $24(1)$ \\
\hline$C(14)$ & $7719(2)$ & $4420(2)$ & $1796(4)$ & $23(1)$ \\
\hline$C(15)$ & $8300(2)$ & $4733(2)$ & $3097(4)$ & $21(1)$ \\
\hline$C(16)$ & $8396(1)$ & $5535(2)$ & $3220(4)$ & $18(1)$ \\
\hline $\mathrm{N}(1)$ & $7536(1)$ & $7434(1)$ & $2261(3)$ & $14(1)$ \\
\hline$C(17)$ & 6891(1) & $8836(2)$ & $2621(3)$ & $13(1)$ \\
\hline$C(18)$ & $6451(1)$ & $9510(2)$ & $2635(3)$ & $15(1)$ \\
\hline$C(21)$ & $6669(1)$ & $10339(2)$ & 2593(3) & $14(1)$ \\
\hline$C(22)$ & $6378(2)$ & $10928(2)$ & $3356(3)$ & 19(1) \\
\hline$C(23)$ & $6587(2)$ & $11714(2)$ & $3323(4)$ & $24(1)$ \\
\hline$C(24)$ & $7075(2)$ & $11909(2)$ & $2546(4)$ & $24(1)$ \\
\hline$C(25)$ & $7353(2)$ & $11331(2)$ & $1795(4)$ & $21(1)$ \\
\hline$C(26)$ & $7158(1)$ & $10557(2)$ & $1819(3)$ & $17(1)$ \\
\hline$C(19)$ & $5814(1)$ & $9193(2)$ & $2679(3)$ & $14(1)$ \\
\hline $\operatorname{Br}(2)$ & 4994(1) & $9724(1)$ & $2730(1)$ & $22(1)$ \\
\hline$C(20)$ & $5862(1)$ & $8362(2)$ & $2727(3)$ & $14(1)$ \\
\hline $\mathrm{C}(27)$ & $5316(1)$ & $7807(2)$ & $2848(3)$ & $14(1)$ \\
\hline
\end{tabular}




$\begin{array}{lllll}\mathrm{C}(28) & 5474(1) & 7232(2) & 4124(3) & 18(1) \\ \mathrm{C}(29) & 4939(2) & 6744(2) & 4257(4) & 22(1) \\ \mathrm{C}(30) & 4239(2) & 6824(2) & 3126(4) & 22(1) \\ \mathrm{C}(31) & 4073(2) & 7388(2) & 1851(4) & 23(1) \\ \mathrm{C}(32) & 4607(1) & 7878(2) & 1717(3) & 15(1) \\ \mathrm{N}(2) & 6517(1) & 8150(1) & 2680(3) & 13(1) \\ \mathrm{N}(3) & 7546(1) & 8842(1) & 2535(3) & 14(1) \\ \mathrm{B} & 6814(2) & 7306(2) & 2613(4) & 16(1) \\ \mathrm{F}(1) & 6972(1) & 6927(1) & 4160(2) & 28(1) \\ \mathrm{F}(2) & 6319(1) & 6893(1) & 1303(2) & 27(1) \\ \end{array}$


Table 3. Bond lengths $[\AA]$ and angles $\left[^{\circ}\right]$ for 19a.

\begin{tabular}{|c|c|}
\hline $\mathrm{C}(1)-\mathrm{N}(3)$ & $1.322(3)$ \\
\hline $\mathrm{C}(1)-\mathrm{N}(1)$ & $1.395(3)$ \\
\hline$C(1)-C(2)$ & $1.439(3)$ \\
\hline$C(2)-C(3)$ & $1.375(4)$ \\
\hline$C(2)-C(5)$ & $1.461(4)$ \\
\hline $\mathrm{C}(5)-\mathrm{C}(10)$ & $1.399(4)$ \\
\hline$C(5)-C(6)$ & $1.407(4)$ \\
\hline$C(6)-C(7)$ & $1.369(4)$ \\
\hline $\mathrm{C}(6)-\mathrm{H}(6)$ & $0.94(3)$ \\
\hline$C(7)-C(8)$ & $1.387(5)$ \\
\hline $\mathrm{C}(7)-\mathrm{H}(7)$ & $0.66(4)$ \\
\hline $\mathrm{C}(8)-\mathrm{C}(9)$ & $1.383(4)$ \\
\hline $\mathrm{C}(8)-\mathrm{H}(8)$ & $0.86(3)$ \\
\hline $\mathrm{C}(9)-\mathrm{C}(10)$ & $1.394(4)$ \\
\hline $\mathrm{C}(9)-\mathrm{H}(9)$ & $0.86(3)$ \\
\hline $\mathrm{C}(10)-\mathrm{H}(10)$ & $1.02(3)$ \\
\hline$C(3)-C(4)$ & $1.429(4)$ \\
\hline $\mathrm{C}(3)-\mathrm{Br}(1)$ & $1.880(2)$ \\
\hline $\mathrm{C}(4)-\mathrm{N}(1)$ & $1.355(3)$ \\
\hline $\mathrm{C}(4)-\mathrm{C}(11)$ & $1.470(4)$ \\
\hline $\mathrm{C}(11)-\mathrm{C}(12)$ & $1.396(4)$ \\
\hline$C(11)-C(16)$ & $1.397(4)$ \\
\hline $\mathrm{C}(12)-\mathrm{C}(13)$ & $1.386(4)$ \\
\hline $\mathrm{C}(12)-\mathrm{H}(12)$ & $0.85(3)$ \\
\hline$C(13)-C(14)$ & $1.380(5)$ \\
\hline $\mathrm{C}(13)-\mathrm{H}(13)$ & $0.90(4)$ \\
\hline$C(14)-C(15)$ & $1.383(4)$ \\
\hline $\mathrm{C}(14)-\mathrm{H}(14)$ & $0.69(4)$ \\
\hline$C(15)-C(16)$ & $1.380(4)$ \\
\hline $\mathrm{C}(15)-\mathrm{H}(15)$ & $0.99(4)$ \\
\hline $\mathrm{C}(16)-\mathrm{H}(16)$ & $0.88(3)$ \\
\hline$N(1)-B$ & $1.568(4)$ \\
\hline $\mathrm{C}(17)-\mathrm{N}(3)$ & $1.322(3)$ \\
\hline $\mathrm{C}(17)-\mathrm{N}(2)$ & $1.393(3)$ \\
\hline
\end{tabular}




\begin{tabular}{|c|c|}
\hline $\mathrm{C}(17)-\mathrm{C}(18)$ & $1.443(4)$ \\
\hline $\mathrm{C}(18)-\mathrm{C}(19)$ & $1.382(4)$ \\
\hline$C(18)-C(21)$ & $1.481(4)$ \\
\hline $\mathrm{C}(21)-\mathrm{C}(26)$ & $1.384(4)$ \\
\hline $\mathrm{C}(21)-\mathrm{C}(22)$ & $1.411(4)$ \\
\hline$C(22)-C(23)$ & $1.405(4)$ \\
\hline $\mathrm{C}(22)-\mathrm{H}(22)$ & $0.88(3)$ \\
\hline$C(23)-C(24)$ & $1.372(5)$ \\
\hline $\mathrm{C}(23)-\mathrm{H}(23)$ & $0.81(4)$ \\
\hline$C(24)-C(25)$ & $1.377(5)$ \\
\hline $\mathrm{C}(24)-\mathrm{H}(24)$ & $0.80(4)$ \\
\hline$C(25)-C(26)$ & $1.377(4)$ \\
\hline $\mathrm{C}(25)-\mathrm{H}(25)$ & $0.70(4)$ \\
\hline $\mathrm{C}(26)-\mathrm{H}(26)$ & $0.94(3)$ \\
\hline$C(19)-C(20)$ & $1.421(4)$ \\
\hline$C(19)-B r(2)$ & $1.870(2)$ \\
\hline $\mathrm{C}(20)-\mathrm{N}(2)$ & $1.359(3)$ \\
\hline$C(20)-C(27)$ & $1.464(3)$ \\
\hline $\mathrm{C}(27)-\mathrm{C}(28)$ & $1.396(4)$ \\
\hline$C(27)-C(32)$ & $1.399(4)$ \\
\hline$C(28)-C(29)$ & $1.381(4)$ \\
\hline $\mathrm{C}(28)-\mathrm{H}(28)$ & $0.90(3)$ \\
\hline$C(29)-C(30)$ & $1.386(4)$ \\
\hline $\mathrm{C}(29)-\mathrm{H}(29)$ & $0.92(4)$ \\
\hline $\mathrm{C}(30)-\mathrm{C}(31)$ & $1.383(4)$ \\
\hline $\mathrm{C}(30)-\mathrm{H}(30)$ & $0.87(4)$ \\
\hline $\mathrm{C}(31)-\mathrm{C}(32)$ & $1.379(4)$ \\
\hline $\mathrm{C}(31)-\mathrm{H}(31)$ & $0.91(3)$ \\
\hline $\mathrm{C}(32)-\mathrm{H}(32)$ & $0.91(3)$ \\
\hline $\mathrm{N}(2)-\mathrm{B}$ & $1.564(3)$ \\
\hline $\mathrm{B}-\mathrm{F}(1)$ & $1.372(4)$ \\
\hline $\mathrm{B}-\mathrm{F}(2)$ & $1.379(3)$ \\
\hline $\mathrm{N}(3)-\mathrm{C}(1)-\mathrm{N}(1)$ & $125.0(2)$ \\
\hline $\mathrm{N}(3)-\mathrm{C}(1)-\mathrm{C}(2)$ & $125.7(2)$ \\
\hline $\mathrm{N}(1)-\mathrm{C}(1)-\mathrm{C}(2)$ & $109.2(2)$ \\
\hline
\end{tabular}




$\begin{array}{ll}\mathrm{C}(3)-\mathrm{C}(2)-\mathrm{C}(1) & 104.8(2) \\ \mathrm{C}(3)-\mathrm{C}(2)-\mathrm{C}(5) & 130.3(2) \\ \mathrm{C}(1)-\mathrm{C}(2)-\mathrm{C}(5) & 124.9(2) \\ \mathrm{C}(10)-\mathrm{C}(5)-\mathrm{C}(6) & 119.5(2) \\ \mathrm{C}(10)-\mathrm{C}(5)-\mathrm{C}(2) & 120.7(2) \\ \mathrm{C}(6)-\mathrm{C}(5)-\mathrm{C}(2) & 119.8(2) \\ \mathrm{C}(7)-\mathrm{C}(6)-\mathrm{C}(5) & 119.4(3) \\ \mathrm{C}(7)-\mathrm{C}(6)-\mathrm{H}(6) & 120.3(18) \\ \mathrm{C}(5)-\mathrm{C}(6)-\mathrm{H}(6) & 120.3(18) \\ \mathrm{C}(6)-\mathrm{C}(7)-\mathrm{C}(8) & 121.7(3) \\ \mathrm{C}(6)-\mathrm{C}(7)-\mathrm{H}(7) & 121(3) \\ \mathrm{C}(8)-\mathrm{C}(7)-\mathrm{H}(7) & 117(3) \\ \mathrm{C}(9)-\mathrm{C}(8)-\mathrm{C}(7) & 119.2(3) \\ \mathrm{C}(9)-\mathrm{C}(8)-\mathrm{H}(8) & 118(2) \\ \mathrm{C}(7)-\mathrm{C}(8)-\mathrm{H}(8) & 122(2) \\ \mathrm{C}(8)-\mathrm{C}(9)-\mathrm{C}(10) & 120.6(3) \\ \mathrm{C}(8)-\mathrm{C}(9)-\mathrm{H}(9) & 122(2) \\ \mathrm{C}(10)-\mathrm{C}(9)-\mathrm{H}(9) & 118(2) \\ \mathrm{C}(9)-\mathrm{C}(10)-\mathrm{C}(5) & 119.6(3) \\ \mathrm{C}(9)-\mathrm{C}(10)-\mathrm{H}(10) & 119.3(19) \\ \mathrm{C}(5)-\mathrm{C}(10)-\mathrm{H}(10) & 121.1(19) \\ \mathrm{C}(2)-\mathrm{C}(3)-\mathrm{C}(4) & 109.8(2) \\ \mathrm{C}(2)-\mathrm{C}(3)-\mathrm{Br}(1) & 126.07(19) \\ \mathrm{C}(4)-\mathrm{C}(3)-\mathrm{Br}(1) & 123.8(2) \\ \mathrm{N}(1)-\mathrm{C}(4)-\mathrm{C}(3) & 107.9(2) \\ \mathrm{N}(1)-\mathrm{C}(4)-\mathrm{C}(11) & 125.5(2) \\ \mathrm{C}(3)-\mathrm{C}(4)-\mathrm{C}(11) & 126.6(2) \\ \mathrm{C}(12)-\mathrm{C}(11)-\mathrm{C}(16) & 118.9(3) \\ \mathrm{C}(12)-\mathrm{C}(11)-\mathrm{C}(4) & 121.2(2) \\ \mathrm{C}(16)-\mathrm{C}(11)-\mathrm{C}(4) & 119.8(2) \\ \mathrm{C}(13)-\mathrm{C}(12)-\mathrm{C}(11) & 120.1(3) \\ \mathrm{C}(13)-\mathrm{C}(12)-\mathrm{H}(12) & 125(2) \\ \mathrm{C}(11)-\mathrm{C}(12)-\mathrm{H}(12) & 114(2) \\ \mathrm{C}(14)-\mathrm{C}(13)-\mathrm{C}(12) & 120.1(3) \\ \mathrm{C}(14)-\mathrm{C}(13)-\mathrm{H}(13) & 122(2) \\ \mathrm{C}(12)-\mathrm{C}(13)-\mathrm{H}(13) & 118(2) \\ & \end{array}$




$\begin{array}{ll}\mathrm{C}(13)-\mathrm{C}(14)-\mathrm{C}(15) & 120.5(3) \\ \mathrm{C}(13)-\mathrm{C}(14)-\mathrm{H}(14) & 130(3) \\ \mathrm{C}(15)-\mathrm{C}(14)-\mathrm{H}(14) & 109(3) \\ \mathrm{C}(16)-\mathrm{C}(15)-\mathrm{C}(14) & 119.7(3) \\ \mathrm{C}(16)-\mathrm{C}(15)-\mathrm{H}(15) & 121(2) \\ \mathrm{C}(14)-\mathrm{C}(15)-\mathrm{H}(15) & 119(2) \\ \mathrm{C}(15)-\mathrm{C}(16)-\mathrm{C}(11) & 120.6(3) \\ \mathrm{C}(15)-\mathrm{C}(16)-\mathrm{H}(16) & 116(2) \\ \mathrm{C}(11)-\mathrm{C}(16)-\mathrm{H}(16) & 123(2) \\ \mathrm{C}(4)-\mathrm{N}(1)-\mathrm{C}(1) & 108.3(2) \\ \mathrm{C}(4)-\mathrm{N}(1)-\mathrm{B} & 128.2(2) \\ \mathrm{C}(1)-\mathrm{N}(1)-\mathrm{B} & 122.2(2) \\ \mathrm{N}(3)-\mathrm{C}(17)-\mathrm{N}(2) & 123.4(2) \\ \mathrm{N}(3)-\mathrm{C}(17)-\mathrm{C}(18) & 126.8(2) \\ \mathrm{N}(2)-\mathrm{C}(17)-\mathrm{C}(18) & 109.8(2) \\ \mathrm{C}(19)-\mathrm{C}(18)-\mathrm{C}(17) & 104.3(2) \\ \mathrm{C}(19)-\mathrm{C}(18)-\mathrm{C}(21) & 130.4(3) \\ \mathrm{C}(17)-\mathrm{C}(18)-\mathrm{C}(21) & 125.3(2) \\ \mathrm{C}(26)-\mathrm{C}(21)-\mathrm{C}(22) & 118.3(2) \\ \mathrm{C}(26)-\mathrm{C}(21)-\mathrm{C}(18) & 121.5(2) \\ \mathrm{C}(22)-\mathrm{C}(21)-\mathrm{C}(18) & 120.2(2) \\ \mathrm{C}(23)-\mathrm{C}(22)-\mathrm{C}(21) & 120.2(3) \\ \mathrm{C}(23)-\mathrm{C}(22)-\mathrm{H}(22) & 119(2) \\ \mathrm{C}(21)-\mathrm{C}(22)-\mathrm{H}(22) & 121(2) \\ \mathrm{C}(24)-\mathrm{C}(23)-\mathrm{C}(22) & 120.0(3) \\ \mathrm{C}(24)-\mathrm{C}(23)-\mathrm{H}(23) & 122(3) \\ \mathrm{C}(22)-\mathrm{C}(23)-\mathrm{H}(23) & 118(3) \\ \mathrm{C}(23)-\mathrm{C}(24)-\mathrm{C}(25) & 119.5(3) \\ \mathrm{C}(23)-\mathrm{C}(24)-\mathrm{H}(24) & 123(3) \\ \mathrm{C}(25)-\mathrm{C}(24)-\mathrm{H}(24) & 117(3) \\ \mathrm{C}(24)-\mathrm{C}(25)-\mathrm{C}(26) & 121.5(3) \\ \mathrm{C}(24)-\mathrm{C}(25)-\mathrm{H}(25) & 121(3) \\ \mathrm{C}(26)-\mathrm{C}(25)-\mathrm{H}(25) & 117(3) \\ \mathrm{C}(25)-\mathrm{C}(26)-\mathrm{C}(21) & 120.5(3) \\ \mathrm{C}(25)-\mathrm{C}(26)-\mathrm{H}(26) & 122(2) \\ \mathrm{C}(21)-\mathrm{C}(26)-\mathrm{H}(26) & 117(2) \\ & \end{array}$




$\begin{array}{ll}\mathrm{C}(18)-\mathrm{C}(19)-\mathrm{C}(20) & 109.8(2) \\ \mathrm{C}(18)-\mathrm{C}(19)-\mathrm{Br}(2) & 128.0(2) \\ \mathrm{C}(20)-\mathrm{C}(19)-\mathrm{Br}(2) & 122.15(19) \\ \mathrm{N}(2)-\mathrm{C}(20)-\mathrm{C}(19) & 108.6(2) \\ \mathrm{N}(2)-\mathrm{C}(20)-\mathrm{C}(27) & 124.3(2) \\ \mathrm{C}(19)-\mathrm{C}(20)-\mathrm{C}(27) & 127.1(2) \\ \mathrm{C}(28)-\mathrm{C}(27)-\mathrm{C}(32) & 118.7(2) \\ \mathrm{C}(28)-\mathrm{C}(27)-\mathrm{C}(20) & 121.8(2) \\ \mathrm{C}(32)-\mathrm{C}(27)-\mathrm{C}(20) & 119.4(2) \\ \mathrm{C}(29)-\mathrm{C}(28)-\mathrm{C}(27) & 120.4(2) \\ \mathrm{C}(29)-\mathrm{C}(28)-\mathrm{H}(28) & 121(2) \\ \mathrm{C}(27)-\mathrm{C}(28)-\mathrm{H}(28) & 118(2) \\ \mathrm{C}(28)-\mathrm{C}(29)-\mathrm{C}(30) & 120.1(3) \\ \mathrm{C}(28)-\mathrm{C}(29)-\mathrm{H}(29) & 125(2) \\ \mathrm{C}(30)-\mathrm{C}(29)-\mathrm{H}(29) & 115(2) \\ \mathrm{C}(31)-\mathrm{C}(30)-\mathrm{C}(29) & 120.3(3) \\ \mathrm{C}(31)-\mathrm{C}(30)-\mathrm{H}(30) & 121(2) \\ \mathrm{C}(29)-\mathrm{C}(30)-\mathrm{H}(30) & 118(2) \\ \mathrm{C}(32)-\mathrm{C}(31)-\mathrm{C}(30) & 119.7(3) \\ \mathrm{C}(32)-\mathrm{C}(31)-\mathrm{H}(31) & 117(2) \\ \mathrm{C}(30)-\mathrm{C}(31)-\mathrm{H}(31) & 123(2) \\ \mathrm{C}(31)-\mathrm{C}(32)-\mathrm{C}(27) & 120.8(2) \\ \mathrm{C}(31)-\mathrm{C}(32)-\mathrm{H}(32) & 121.2(18) \\ \mathrm{C}(27)-\mathrm{C}(32)-\mathrm{H}(32) & 117.5(18) \\ \mathrm{C}(20)-\mathrm{N}(2)-\mathrm{C}(17) & 107.5(2) \\ \mathrm{C}(20)-\mathrm{N}(2)-\mathrm{B} & 128.2(2) \\ \mathrm{C}(17)-\mathrm{N}(2)-\mathrm{B} & 124.2(2) \\ \mathrm{C}(17)-\mathrm{N}(3)-\mathrm{C}(1) & 119.5(2) \\ \mathrm{F}(1)-\mathrm{B}-\mathrm{F}(2) & 111.6(2) \\ \mathrm{F}(1)-\mathrm{B}-\mathrm{N}(2) & 111.5(2) \\ \mathrm{F}(2)-\mathrm{B}-\mathrm{N}(2) & 108.9(2) \\ \mathrm{F}(1)-\mathrm{B}-\mathrm{N}(1) & 108.1(2) \\ \mathrm{F}(2)-\mathrm{B}-\mathrm{N}(1) & 111.7(2) \\ \mathrm{N}(2)-\mathrm{B}-\mathrm{N}(1) & 104.8(2) \\ & \end{array}$


Table 4. Anisotropic displacement parameters $\left(\AA^{2} \mathrm{x} 10^{3}\right)$ for 19a.

\begin{tabular}{|c|c|c|c|c|c|c|}
\hline Atom & $\mathrm{U}^{11}$ & $\mathrm{U}^{22}$ & $\mathrm{U}^{33}$ & $\mathrm{U}^{23}$ & $\mathrm{U}^{13}$ & $\mathrm{U}^{12}$ \\
\hline $\mathrm{C}(1)$ & $12(1)$ & $10(1)$ & $17(1)$ & $1(1)$ & $4(1)$ & $0(1)$ \\
\hline $\mathrm{C}(2)$ & $12(1)$ & $19(1)$ & $15(1)$ & $-1(1)$ & $5(1)$ & 1(1) \\
\hline$C(5)$ & $15(1)$ & $12(1)$ & $20(1)$ & $-3(1)$ & $9(1)$ & $1(1)$ \\
\hline$C(6)$ & $18(1)$ & $18(1)$ & $20(1)$ & $-3(1)$ & $7(1)$ & $0(1)$ \\
\hline$C(7)$ & $30(2)$ & $12(1)$ & $30(2)$ & $3(1)$ & $15(1)$ & $2(1)$ \\
\hline$C(8)$ & $25(1)$ & $19(1)$ & $40(2)$ & $-7(1)$ & $21(1)$ & $-11(1)$ \\
\hline $\mathrm{C}(9)$ & $15(1)$ & $22(2)$ & $28(1)$ & $-6(1)$ & $7(1)$ & $-2(1)$ \\
\hline$C(10)$ & $15(1)$ & $16(1)$ & $22(1)$ & $-4(1)$ & $7(1)$ & $-1(1)$ \\
\hline$C(3)$ & $11(1)$ & $13(1)$ & $22(1)$ & $-1(1)$ & $7(1)$ & $2(1)$ \\
\hline $\operatorname{Br}(1)$ & $15(1)$ & $14(1)$ & $33(1)$ & $-2(1)$ & $13(1)$ & $2(1)$ \\
\hline$C(4)$ & $12(1)$ & $14(1)$ & $14(1)$ & $-1(1)$ & $4(1)$ & $2(1)$ \\
\hline $\mathrm{C}(11)$ & $14(1)$ & $14(1)$ & $25(1)$ & $1(1)$ & $12(1)$ & $1(1)$ \\
\hline$C(12)$ & $15(1)$ & $20(1)$ & $25(1)$ & $-4(1)$ & $7(1)$ & $2(1)$ \\
\hline$C(13)$ & $18(1)$ & $23(2)$ & $31(2)$ & $-9(1)$ & $7(1)$ & $-5(1)$ \\
\hline$C(14)$ & $24(2)$ & $14(2)$ & $36(2)$ & $-2(1)$ & $17(1)$ & $-3(1)$ \\
\hline$C(15)$ & $22(1)$ & $14(1)$ & $29(1)$ & $3(1)$ & $11(1)$ & $3(1)$ \\
\hline$C(16)$ & $14(1)$ & $15(1)$ & $23(1)$ & $-1(1)$ & $5(1)$ & $-1(1)$ \\
\hline $\mathrm{N}(1)$ & $11(1)$ & $10(1)$ & $19(1)$ & $0(1)$ & $5(1)$ & $-1(1)$ \\
\hline$C(17)$ & $12(1)$ & $13(1)$ & $14(1)$ & $0(1)$ & $4(1)$ & $-1(1)$ \\
\hline$C(18)$ & $13(1)$ & $14(1)$ & $16(1)$ & $2(1)$ & $3(1)$ & $1(1)$ \\
\hline$C(21)$ & $11(1)$ & 11(1) & $16(1)$ & $0(1)$ & $0(1)$ & $2(1)$ \\
\hline$C(22)$ & $22(1)$ & $16(1)$ & $19(1)$ & $2(1)$ & $7(1)$ & $3(1)$ \\
\hline$C(23)$ & $31(2)$ & $16(1)$ & $21(1)$ & $-4(1)$ & $4(1)$ & $5(1)$ \\
\hline$C(24)$ & $27(2)$ & $14(2)$ & $24(1)$ & $1(1)$ & $-2(1)$ & $-10(1)$ \\
\hline$C(25)$ & $16(1)$ & $23(2)$ & $23(1)$ & $3(1)$ & $4(1)$ & $-5(1)$ \\
\hline$C(26)$ & $14(1)$ & $18(1)$ & $18(1)$ & $2(1)$ & $4(1)$ & $4(1)$ \\
\hline$C(19)$ & $12(1)$ & $16(1)$ & $16(1)$ & $1(1)$ & $5(1)$ & $5(1)$ \\
\hline $\operatorname{Br}(2)$ & $14(1)$ & $16(1)$ & $38(1)$ & $-4(1)$ & 11(1) & $3(1)$ \\
\hline$C(20)$ & $11(1)$ & $14(1)$ & $15(1)$ & $1(1)$ & $2(1)$ & $2(1)$ \\
\hline$C(27)$ & $12(1)$ & $12(1)$ & $20(1)$ & $-4(1)$ & $9(1)$ & $0(1)$ \\
\hline
\end{tabular}




\begin{tabular}{lrrrrrr}
$\mathrm{C}(28)$ & $14(1)$ & $19(1)$ & $22(1)$ & $0(1)$ & $6(1)$ & $2(1)$ \\
$\mathrm{C}(29)$ & $23(1)$ & $20(1)$ & $22(1)$ & $4(1)$ & $9(1)$ & $-1(1)$ \\
$\mathrm{C}(30)$ & $19(1)$ & $22(2)$ & $29(1)$ & $-1(1)$ & $12(1)$ & $-6(1)$ \\
$\mathrm{C}(31)$ & $15(1)$ & $26(2)$ & $25(1)$ & $1(1)$ & $4(1)$ & $-1(1)$ \\
$\mathrm{C}(32)$ & $17(1)$ & $13(1)$ & $18(1)$ & $2(1)$ & $7(1)$ & $-1(1)$ \\
$\mathrm{N}(2)$ & $10(1)$ & $12(1)$ & $18(1)$ & $3(1)$ & $5(1)$ & $1(1)$ \\
$\mathrm{N}(3)$ & $11(1)$ & $12(1)$ & $16(1)$ & $1(1)$ & $2(1)$ & $0(1)$ \\
$\mathrm{B}$ & $14(1)$ & $9(1)$ & $26(1)$ & $-2(1)$ & $9(1)$ & $2(1)$ \\
$\mathrm{F}(1)$ & $30(1)$ & $22(1)$ & $41(1)$ & $16(1)$ & $22(1)$ & $13(1)$ \\
$\mathrm{F}(2)$ & $14(1)$ & $19(1)$ & $48(1)$ & $-14(1)$ & $11(1)$ & $-6(1)$ \\
& & & & & & \\
\hline
\end{tabular}


Table 5. Hydrogen coordinates ( x 104) and isotropic displacement parameters $\left(\AA^{2} \times 10^{3}\right)$ for 19a.

\begin{tabular}{lrrrr}
\hline Atom & \multicolumn{1}{c}{$\mathrm{x}$} & $\mathrm{y}$ & $\mathrm{z}$ & $\mathrm{U}(\mathrm{eq})$ \\
& & & & \\
\hline $\mathrm{H}(6)$ & $8316(15)$ & $9400(17)$ & $490(30)$ & $6(6)$ \\
$\mathrm{H}(7)$ & $9150(20)$ & $10300(20)$ & $780(50)$ & $20(10)$ \\
$\mathrm{H}(8)$ & $10260(19)$ & $10360(20)$ & $2400(40)$ & $22(9)$ \\
$\mathrm{H}(9)$ & $10670(16)$ & $9309(18)$ & $4090(40)$ & $10(7)$ \\
$\mathrm{H}(10)$ & $9973(19)$ & $8247(19)$ & $4200(40)$ & $20(8)$ \\
$\mathrm{H}(12)$ & $7090(17)$ & $6040(20)$ & $0(40)$ & $15(7)$ \\
$\mathrm{H}(13)$ & $6840(20)$ & $4720(20)$ & $-210(50)$ & $32(10)$ \\
$\mathrm{H}(14)$ & $7700(20)$ & $4020(20)$ & $1940(50)$ & $32(11)$ \\
$\mathrm{H}(15)$ & $8610(20)$ & $4370(20)$ & $3990(50)$ & $38(10)$ \\
$\mathrm{H}(16)$ & $8757(17)$ & $5700(20)$ & $4110(40)$ & $25(9)$ \\
$\mathrm{H}(22)$ & $6083(15)$ & $10809(18)$ & $3910(40)$ & $11(7)$ \\
$\mathrm{H}(23)$ & $6412(18)$ & $12040(20)$ & $3780(40)$ & $21(8)$ \\
$\mathrm{H}(24)$ & $7234(19)$ & $12340(30)$ & $2580(50)$ & $33(11)$ \\
$\mathrm{H}(25)$ & $7610(20)$ & $11420(20)$ & $1430(50)$ & $30(11)$ \\
$\mathrm{H}(26)$ & $7347(18)$ & $10160(20)$ & $1320(40)$ & $20(8)$ \\
$\mathrm{H}(28)$ & $5939(18)$ & $7150(20)$ & $4780(40)$ & $17(7)$ \\
$\mathrm{H}(29)$ & $5004(18)$ & $6360(20)$ & $5070(40)$ & $20(8)$ \\
$\mathrm{H}(30)$ & $3910(19)$ & $6510(20)$ & $3250(40)$ & $28(9)$ \\
$\mathrm{H}(31)$ & $3619(19)$ & $7470(20)$ & $1090(40)$ & $23(8)$ \\
$\mathrm{H}(32)$ & $4524(15)$ & $8211(17)$ & $820(40)$ & $9(7)$ \\
& & & & \\
\hline & & & &
\end{tabular}


Table 6. Torsion angles $\left[{ }^{\circ}\right]$ for $19 a$.

\begin{tabular}{cl}
\hline $\mathrm{N}(3)-\mathrm{C}(1)-\mathrm{C}(2)-\mathrm{C}(3)$ & $175.7(2)$ \\
$\mathrm{N}(1)-\mathrm{C}(1)-\mathrm{C}(2)-\mathrm{C}(3)$ & $-1.7(3)$ \\
$\mathrm{N}(3)-\mathrm{C}(1)-\mathrm{C}(2)-\mathrm{C}(5)$ & $-4.4(4)$ \\
$\mathrm{N}(1)-\mathrm{C}(1)-\mathrm{C}(2)-\mathrm{C}(5)$ & $178.2(2)$ \\
$\mathrm{C}(3)-\mathrm{C}(2)-\mathrm{C}(5)-\mathrm{C}(10)$ & $-46.8(4)$ \\
$\mathrm{C}(1)-\mathrm{C}(2)-\mathrm{C}(5)-\mathrm{C}(10)$ & $133.4(3)$ \\
$\mathrm{C}(3)-\mathrm{C}(2)-\mathrm{C}(5)-\mathrm{C}(6)$ & $131.9(3)$ \\
$\mathrm{C}(1)-\mathrm{C}(2)-\mathrm{C}(5)-\mathrm{C}(6)$ & $-48.0(4)$ \\
$\mathrm{C}(10)-\mathrm{C}(5)-\mathrm{C}(6)-\mathrm{C}(7)$ & $0.1(4)$ \\
$\mathrm{C}(2)-\mathrm{C}(5)-\mathrm{C}(6)-\mathrm{C}(7)$ & $-178.6(2)$ \\
$\mathrm{C}(5)-\mathrm{C}(6)-\mathrm{C}(7)-\mathrm{C}(8)$ & $-0.5(4)$ \\
$\mathrm{C}(6)-\mathrm{C}(7)-\mathrm{C}(8)-\mathrm{C}(9)$ & $-0.4(4)$ \\
$\mathrm{C}(7)-\mathrm{C}(8)-\mathrm{C}(9)-\mathrm{C}(10)$ & $1.6(4)$ \\
$\mathrm{C}(8)-\mathrm{C}(9)-\mathrm{C}(10)-\mathrm{C}(5)$ & $-2.0(4)$ \\
$\mathrm{C}(6)-\mathrm{C}(5)-\mathrm{C}(10)-\mathrm{C}(9)$ & $1.1(4)$ \\
$\mathrm{C}(2)-\mathrm{C}(5)-\mathrm{C}(10)-\mathrm{C}(9)$ & $179.8(2)$ \\
$\mathrm{C}(1)-\mathrm{C}(2)-\mathrm{C}(3)-\mathrm{C}(4)$ & $1.3(3)$ \\
$\mathrm{C}(5)-\mathrm{C}(2)-\mathrm{C}(3)-\mathrm{C}(4)$ & $-178.5(3)$ \\
$\mathrm{C}(1)-\mathrm{C}(2)-\mathrm{C}(3)-\mathrm{Br}(1)$ & $175.47(19)$ \\
$\mathrm{C}(5)-\mathrm{C}(2)-\mathrm{C}(3)-\mathrm{Br}(1)$ & $-4.4(4)$ \\
$\mathrm{C}(2)-\mathrm{C}(3)-\mathrm{C}(4)-\mathrm{N}(1)$ & $-0.5(3)$ \\
$\mathrm{Br}(1)-\mathrm{C}(3)-\mathrm{C}(4)-\mathrm{N}(1)$ & $-174.82(18)$ \\
$\mathrm{C}(2)-\mathrm{C}(3)-\mathrm{C}(4)-\mathrm{C}(11)$ & $178.2(3)$ \\
$\mathrm{Br}(1)-\mathrm{C}(3)-\mathrm{C}(4)-\mathrm{C}(11)$ & $3.9(4)$ \\
$\mathrm{N}(1)-\mathrm{C}(4)-\mathrm{C}(11)-\mathrm{C}(12)$ & $54.0(4)$ \\
$\mathrm{C}(3)-\mathrm{C}(4)-\mathrm{C}(11)-\mathrm{C}(12)$ & $-124.6(3)$ \\
$\mathrm{N}(1)-\mathrm{C}(4)-\mathrm{C}(11)-\mathrm{C}(16)$ & $-128.9(3)$ \\
$\mathrm{C}(3)-\mathrm{C}(4)-\mathrm{C}(11)-\mathrm{C}(16)$ & $52.5(4)$ \\
$\mathrm{C}(16)-\mathrm{C}(11)-\mathrm{C}(12)-\mathrm{C}(13)$ & $0.2(4)$ \\
$\mathrm{C}(4)-\mathrm{C}(11)-\mathrm{C}(12)-\mathrm{C}(13)$ & $177.3(3)$ \\
$\mathrm{C}(11)-\mathrm{C}(12)-\mathrm{C}(13)-\mathrm{C}(14)$ & $0.6(4)$ \\
$\mathrm{C}(12)-\mathrm{C}(13)-\mathrm{C}(14)-\mathrm{C}(15)$ & $-0.3(5)$ \\
$\mathrm{C}(13)-\mathrm{C}(14)-\mathrm{C}(15)-\mathrm{C}(16)$ & $-0.9(4)$ \\
$\mathrm{C}(14)-\mathrm{C}(15)-\mathrm{C}(16)-\mathrm{C}(11)$ & $1.7(4)$ \\
&
\end{tabular}




$$
\begin{aligned}
& \mathrm{C}(12)-\mathrm{C}(11)-\mathrm{C}(16)-\mathrm{C}(15)-1.3(4) \\
& \text { C(4)-C(11)-C(16)-C(15) -178.5(2) } \\
& \mathrm{C}(3)-\mathrm{C}(4)-\mathrm{N}(1)-\mathrm{C}(1) \quad-0.6(3) \\
& \mathrm{C}(11)-\mathrm{C}(4)-\mathrm{N}(1)-\mathrm{C}(1) \quad-179.3(2) \\
& \mathrm{C}(3)-\mathrm{C}(4)-\mathrm{N}(1)-\mathrm{B} \quad-167.0(2) \\
& \mathrm{C}(11)-\mathrm{C}(4)-\mathrm{N}(1)-\mathrm{B} \quad 14.3(4) \\
& \mathrm{N}(3)-\mathrm{C}(1)-\mathrm{N}(1)-\mathrm{C}(4) \quad-176.0(2) \\
& \mathrm{C}(2)-\mathrm{C}(1)-\mathrm{N}(1)-\mathrm{C}(4) \quad 1.4(3) \\
& \mathrm{N}(3)-\mathrm{C}(1)-\mathrm{N}(1)-\mathrm{B} \quad-8.6(4) \\
& \mathrm{C}(2)-\mathrm{C}(1)-\mathrm{N}(1)-\mathrm{B} \quad 168.8(2) \\
& \mathrm{N}(3)-\mathrm{C}(17)-\mathrm{C}(18)-\mathrm{C}(19) \quad 178.1(2) \\
& \mathrm{N}(2)-\mathrm{C}(17)-\mathrm{C}(18)-\mathrm{C}(19) \quad-0.8(3) \\
& \mathrm{N}(3)-\mathrm{C}(17)-\mathrm{C}(18)-\mathrm{C}(21)-1.5(4) \\
& \mathrm{N}(2)-\mathrm{C}(17)-\mathrm{C}(18)-\mathrm{C}(21) \quad 179.7(2) \\
& \mathrm{C}(19)-\mathrm{C}(18)-\mathrm{C}(21)-\mathrm{C}(26)-151.0(3) \\
& \text { C(17)-C(18)-C(21)-C(26) 28.5(4) } \\
& \text { C(19)-C(18)-C(21)-C(22) 29.2(4) } \\
& \mathrm{C}(17)-\mathrm{C}(18)-\mathrm{C}(21)-\mathrm{C}(22) \quad-151.4(3) \\
& \mathrm{C}(26)-\mathrm{C}(21)-\mathrm{C}(22)-\mathrm{C}(23)-0.1(4) \\
& \mathrm{C}(18)-\mathrm{C}(21)-\mathrm{C}(22)-\mathrm{C}(23) \quad 179.7(2) \\
& \mathrm{C}(21)-\mathrm{C}(22)-\mathrm{C}(23)-\mathrm{C}(24) \quad 0.0(4) \\
& \mathrm{C}(22)-\mathrm{C}(23)-\mathrm{C}(24)-\mathrm{C}(25) \quad 0.4(4) \\
& \mathrm{C}(23)-\mathrm{C}(24)-\mathrm{C}(25)-\mathrm{C}(26)-0.7(4) \\
& \mathrm{C}(24)-\mathrm{C}(25)-\mathrm{C}(26)-\mathrm{C}(21) \quad 0.6(4) \\
& \mathrm{C}(22)-\mathrm{C}(21)-\mathrm{C}(26)-\mathrm{C}(25) \quad-0.2(4) \\
& \mathrm{C}(18)-\mathrm{C}(21)-\mathrm{C}(26)-\mathrm{C}(25) \quad 179.9(2) \\
& \mathrm{C}(17)-\mathrm{C}(18)-\mathrm{C}(19)-\mathrm{C}(20) \quad 1.2(3) \\
& \mathrm{C}(21)-\mathrm{C}(18)-\mathrm{C}(19)-\mathrm{C}(20) \quad-179.3(3) \\
& \text { C(17)-C(18)-C(19)-Br(2) 179.64(19) } \\
& \mathrm{C}(21)-\mathrm{C}(18)-\mathrm{C}(19)-\mathrm{Br}(2) \quad-0.8(4) \\
& \mathrm{C}(18)-\mathrm{C}(19)-\mathrm{C}(20)-\mathrm{N}(2) \quad-1.2(3) \\
& \mathrm{Br}(2)-\mathrm{C}(19)-\mathrm{C}(20)-\mathrm{N}(2) \quad-179.77(17) \\
& \mathrm{C}(18)-\mathrm{C}(19)-\mathrm{C}(20)-\mathrm{C}(27) \quad 177.5(2) \\
& \mathrm{Br}(2)-\mathrm{C}(19)-\mathrm{C}(20)-\mathrm{C}(27) \quad-1.1(4) \\
& \mathrm{N}(2)-\mathrm{C}(20)-\mathrm{C}(27)-\mathrm{C}(28) \quad 52.4(4) \\
& \mathrm{C}(19)-\mathrm{C}(20)-\mathrm{C}(27)-\mathrm{C}(28) \quad-126.1(3)
\end{aligned}
$$




$$
\begin{array}{ll}
\mathrm{N}(2)-\mathrm{C}(20)-\mathrm{C}(27)-\mathrm{C}(32) & -131.2(3) \\
\mathrm{C}(19)-\mathrm{C}(20)-\mathrm{C}(27)-\mathrm{C}(32) & 50.3(4) \\
\mathrm{C}(32)-\mathrm{C}(27)-\mathrm{C}(28)-\mathrm{C}(29) & 0.2(4) \\
\mathrm{C}(20)-\mathrm{C}(27)-\mathrm{C}(28)-\mathrm{C}(29) & 176.7(2) \\
\mathrm{C}(27)-\mathrm{C}(28)-\mathrm{C}(29)-\mathrm{C}(30) & -0.3(4) \\
\mathrm{C}(28)-\mathrm{C}(29)-\mathrm{C}(30)-\mathrm{C}(31) & 0.4(4) \\
\mathrm{C}(29)-\mathrm{C}(30)-\mathrm{C}(31)-\mathrm{C}(32) & -0.5(4) \\
\mathrm{C}(30)-\mathrm{C}(31)-\mathrm{C}(32)-\mathrm{C}(27) & 0.5(4) \\
\mathrm{C}(28)-\mathrm{C}(27)-\mathrm{C}(32)-\mathrm{C}(31) & -0.4(4) \\
\mathrm{C}(20)-\mathrm{C}(27)-\mathrm{C}(32)-\mathrm{C}(31) & -176.9(2) \\
\mathrm{C}(19)-\mathrm{C}(20)-\mathrm{N}(2)-\mathrm{C}(17) & 0.7(3) \\
\mathrm{C}(27)-\mathrm{C}(20)-\mathrm{N}(2)-\mathrm{C}(17) & -178.1(2) \\
\mathrm{C}(19)-\mathrm{C}(20)-\mathrm{N}(2)-\mathrm{B} & -176.7(2) \\
\mathrm{C}(27)-\mathrm{C}(20)-\mathrm{N}(2)-\mathrm{B} & 4.6(4) \\
\mathrm{N}(3)-\mathrm{C}(17)-\mathrm{N}(2)-\mathrm{C}(20) & -178.8(2) \\
\mathrm{C}(18)-\mathrm{C}(17)-\mathrm{N}(2)-\mathrm{C}(20) & 0.1(3) \\
\mathrm{N}(3)-\mathrm{C}(17)-\mathrm{N}(2)-\mathrm{B} & -1.3(4) \\
\mathrm{C}(18)-\mathrm{C}(17)-\mathrm{N}(2)-\mathrm{B} & 177.5(2) \\
\mathrm{N}(2)-\mathrm{C}(17)-\mathrm{N}(3)-\mathrm{C}(1) & 5.7(4) \\
\mathrm{C}(18)-\mathrm{C}(17)-\mathrm{N}(3)-\mathrm{C}(1) & -173.0(2) \\
\mathrm{N}(1)-\mathrm{C}(1)-\mathrm{N}(3)-\mathrm{C}(17) & -0.6(4) \\
\mathrm{C}(2)-\mathrm{C}(1)-\mathrm{N}(3)-\mathrm{C}(17) & -177.6(2) \\
\mathrm{C}(20)-\mathrm{N}(2)-\mathrm{B}-\mathrm{F}(1) & -72.7(3) \\
\mathrm{C}(17)-\mathrm{N}(2)-\mathrm{B}-\mathrm{F}(1) & 110.4(3) \\
\mathrm{C}(20)-\mathrm{N}(2)-\mathrm{B}-\mathrm{F}(2) & 50.9(4) \\
\mathrm{C}(17)-\mathrm{N}(2)-\mathrm{B}-\mathrm{F}(2) & -126.0(2) \\
\mathrm{C}(20)-\mathrm{N}(2)-\mathrm{B}-\mathrm{N}(1) & 170.6(2) \\
\mathrm{C}(17)-\mathrm{N}(2)-\mathrm{B}-\mathrm{N}(1) & -6.4(3) \\
\mathrm{C}(4)-\mathrm{N}(1)-\mathrm{B}-\mathrm{F}(1) & 56.4(3) \\
\mathrm{C}(1)-\mathrm{N}(1)-\mathrm{B}-\mathrm{F}(1) & -108.3(3) \\
\mathrm{C}(4)-\mathrm{N}(1)-\mathrm{B}-\mathrm{F}(2) & -66.8(3) \\
\mathrm{C}(1)-\mathrm{N}(1)-\mathrm{B}-\mathrm{F}(2) & 128.5(2) \\
\mathrm{C}(4)-\mathrm{N}(1)-\mathrm{B}-\mathrm{N}(2) & 175.5(2) \\
\mathrm{C}(1)-\mathrm{N}(1)-\mathrm{B}-\mathrm{N}(2) & 10.8(3) \\
&
\end{array}
$$




\section{Comparative Singlet oxygen Generation Plots}
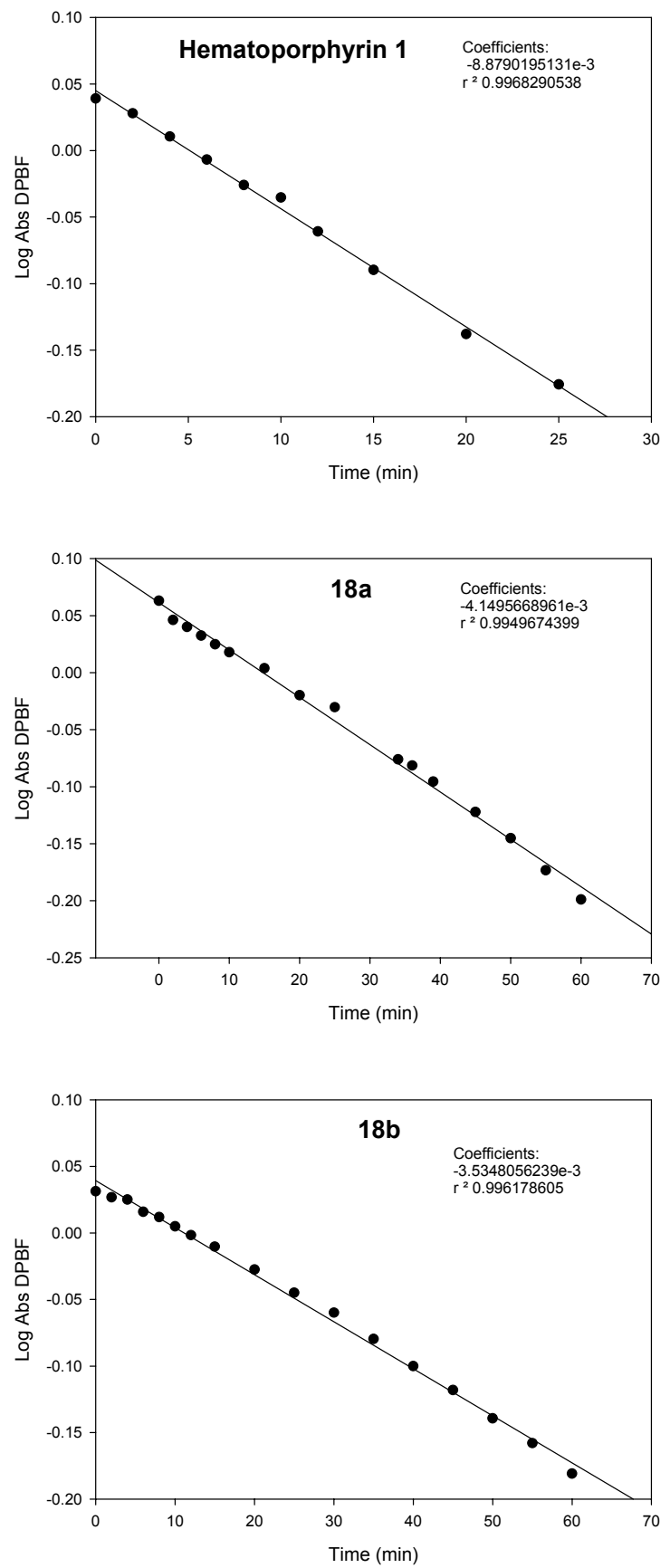

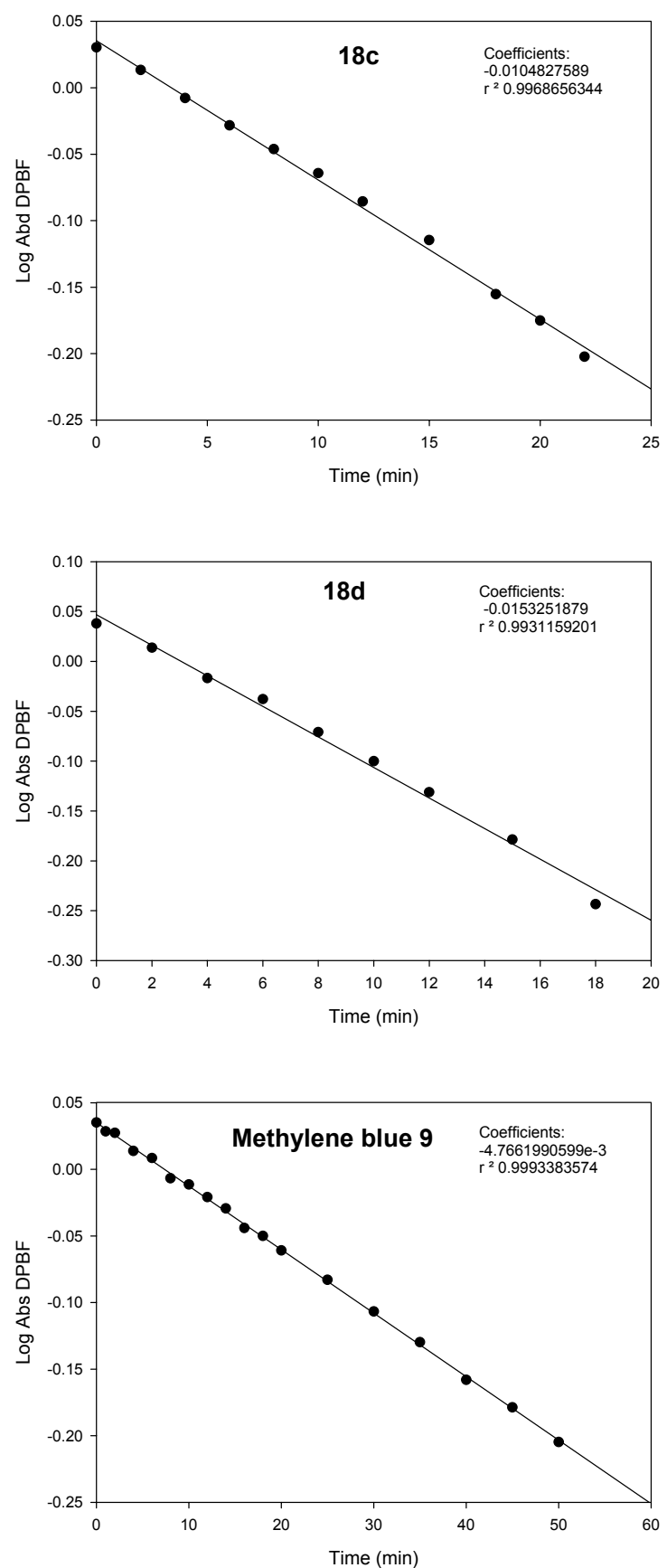

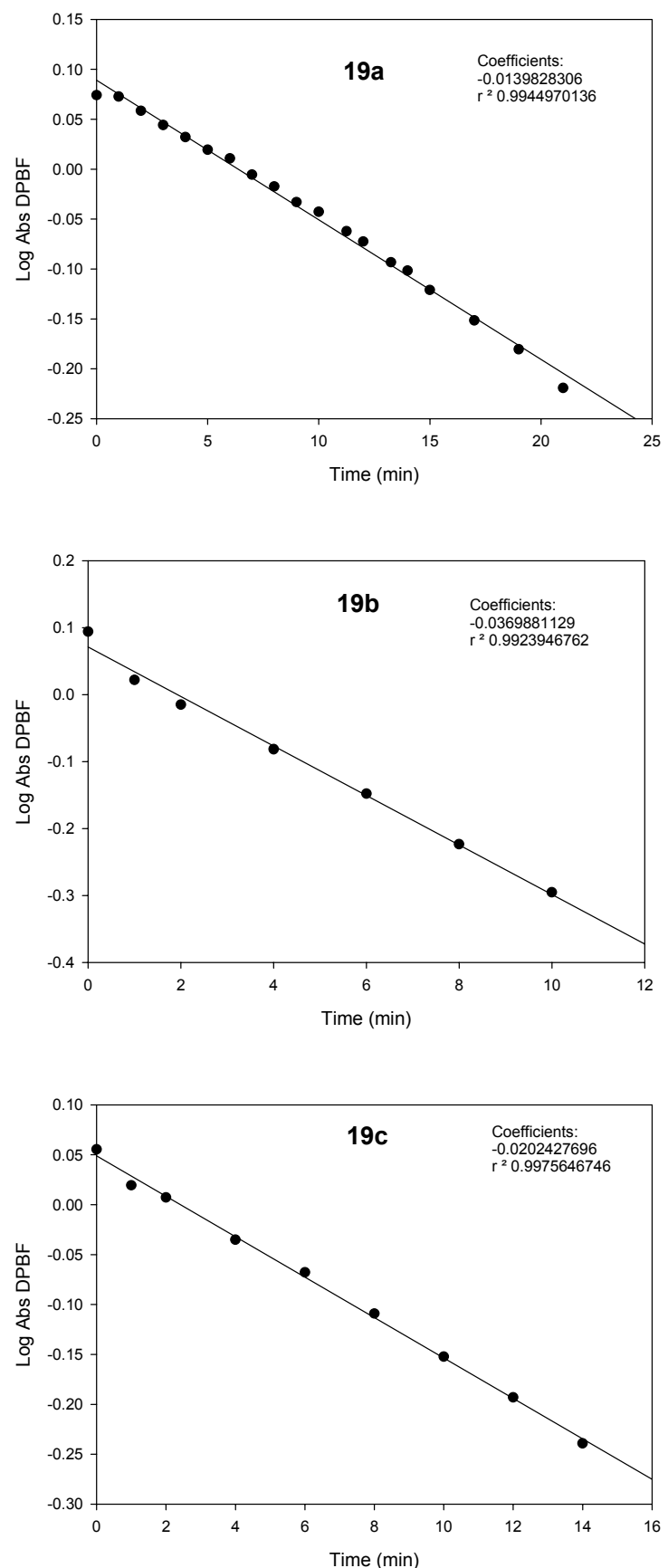
Overlay of UV-Visible spectra, at a series of time points over 2 hours, of an irradiated IPA solution of DPBF and 18a.

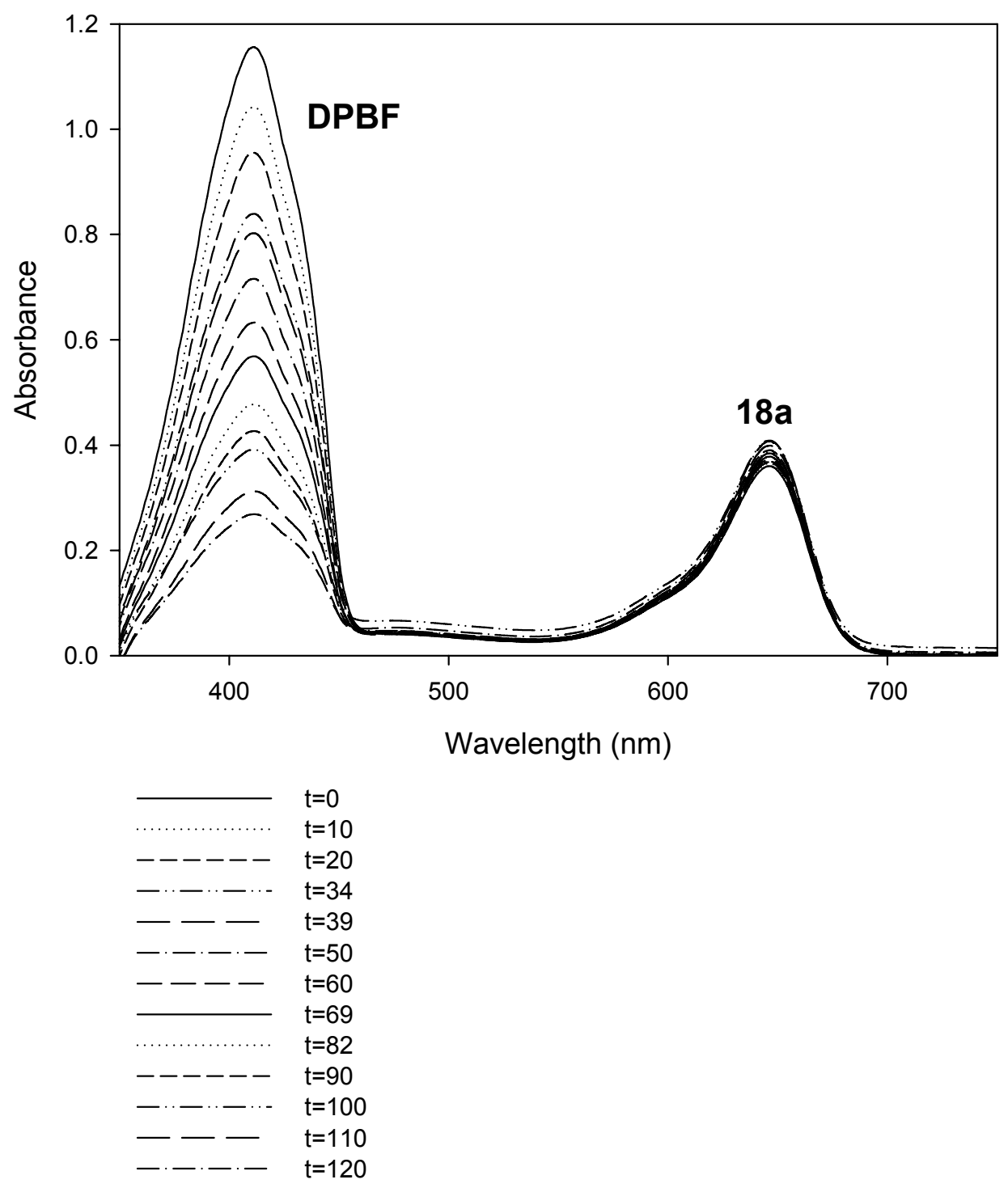

